\title{
Business Combinations e Consolidação das Demonstrações Contábeis: Uma Abordagem Comparativa Entre os Pronunciamentos e Normas dos US-GAAP, IASC e Brasil.
}

\author{
Zaina Said El Hajj \\ Doutoranda e Mestre em Controladoria e Contabili- \\ dade pela FEA/USP
}

RESUMO

Este estudo apresenta uma abordagem comparativa entre os pronunciamentos e normas contábeis do IASB, US-GAAP e Brasil (BR-GAAP) para as operações de business combinations (fusão, incorporação ou aquisição de controle) e para a consolidação das demonstrações contábeis.

Inicialmente, focaliza-se o tratamento contábil, contemplando-se os métodos de avaliação: pooling, que mantém os valores contábeis; e purchase, que modifica os valores contábeis das empresas fruto de business combination.

Define-se business combinations de acordo com os conceitos contidos nos US-GAAP, IASB e nos pronunciamentos brasileiros para, em seguida, apresentar a definição adotada neste estudo. São destacadas algumas estatísticas das operações de business combinations e as principais dificuldades relacionadas ao tema, assim como a questão a ser investigada.

$\mathrm{Na}$ análise comparativa, são tratados os principais pronunciamentos e normas contábeis emitidos, destacando-se as definições, o tratamento contábil, os métodos de avaliação, a consolidação e as evidenciações exigidas.

O estudo inclui uma análise dos mais significativos procedimentos de consolidação e as evidenciações exigidas.

Finalmente, são esclarecidas as principais similaridades e diferenças abordadas e as constatações do estudo.

Palavras-chave: Demonstrações Financeiras; Fusões e Aquisições; Incorporação; Métodos de Avaliação; Demonstrações Contábeis Consolidadas.

\author{
Lázaro Plácido Lisboa \\ Prof. Dr. do Depto. de Contabilidade e Atuária \\ FEA/USP
}

ABSTRACT

This study presents a comparative analysis among the IASB, US-GAAP and Brazilian (BR-GAAP) accounting pronouncements for the transactions of business combinations (consolidation, merger or control acquisition) and for the consolidation of financial statements.

Initially, it focalizes the accounting treatment and contemplates the methods of evaluation: pooling, that carry on the book values; and purchase, that modify the book values of remaining entities of business combination.

It reviews the definition of business combinations according to the concepts of IASB, US-GAAP and Brazilian pronouncements and, subsequently, the definition used in this study. This study offers some statistics of the transactions of business combinations and gives a survey of how the main difficulties related to this subject were approached, as well as a determination of the most important issue of this study.

In the comparative analysis, the main rules of accountancy are trated, highlighting the definitions, accounting treatment, methods of evaluation, consolidation and disclosure.

Moreover, this study includes an analysis of the most sinificant procedures for consolidation, as well as some examples related to US-GAAP, IASB and BR-GAAP.

Finally, some of the main similarities and differences are cleared up and the conclusions that were made on the basis of analysis are discussed.

Key words: Financial Statements; Mergers and Acquisitions; Merger; Methods of Evaluation; Consolidated Financial Statements. 
INTRODUÇÃO

Grandes mudanças de regulamentações e de tecnologia numa conjuntura de significativa disputa de mercado e uma crescente necessidade de reduzir custos estimularam as associações, coligações, fusões, incorporações e aquisições de empresas.

Diante das novas condições do mercado, surgem novos desafios para os estudiosos e profissionais da contabilidade. A abertura da economia, decorrente do processo de globalização, acirrou a concorrência e aumentou as operações denominadas internacionalmente de business combinations.

Os pronunciamentos e normas contábeis internacionais estabelecem dois métodos de contabilização para as operações de business combinations: purchase e pooling of interests.

A diferença principal entre eles é a base de reconhecimento dos ativos líquidos ${ }^{1}$ das empresas combinadas ou investidas. Tem-se, de forma genérica, a manutenção dos valores contábeis ou o reconhecimento dos novos valores de mercado dos ativos e passivos das empresas combinadas.

No pooling, a(s) empresa(s) resultante(s) de uma business combination ${ }^{2}$ contabiliza(m) os ativos líquidos de acordo com os respectivos valores contábeis dos ativos e passivos das empresas combinadas anteriormente existentes. A forma de pagamento é realizada, basicamente, por meio da troca de ações entre os acionistas controladores. Estes efetivamente com- partilham o controle a partir da transação, não havendo a figura do comprador e a do vendedor.

Diferentemente, no purchase, o parâmetro básico para o reconhecimento dos ativos líquidos da sociedade investida é o valor de mercado (fair value), que representa o valor efetivo de cada ativo e passivo adquiridos. A forma de pagamento na aquisição da(s) sociedade(s) investida(s) é realizada, principalmente, em moeda corrente.

No purchase, não permanecem os valores históricos de custo da investida porque só tinham significado como custo exatamente para os antigos acionistas proprietários da adquirida, mas não mais para os novos.

No Brasil e em outros países, não existe, de forma explícita, denominação específica de métodos de avaliação para as operações de fusão, incorporação e aquisição de controle; entretanto, essas transações podem ser avaliadas pelo valor contábil ou pelo valor de mercado.

Portanto, podem existir diferenças significativas de práticas contábeis adotadas no Brasil em relação aos princípios, normas e práticas estrangeiros.

\section{DEFINIÇÕES}

Para compreender as operações de business combinations, pesquisaram-se algumas definições constantes nas normas societárias e nos pronunciamentos contábeis nacionais e estrangeiros, conforme o quadro seguinte.

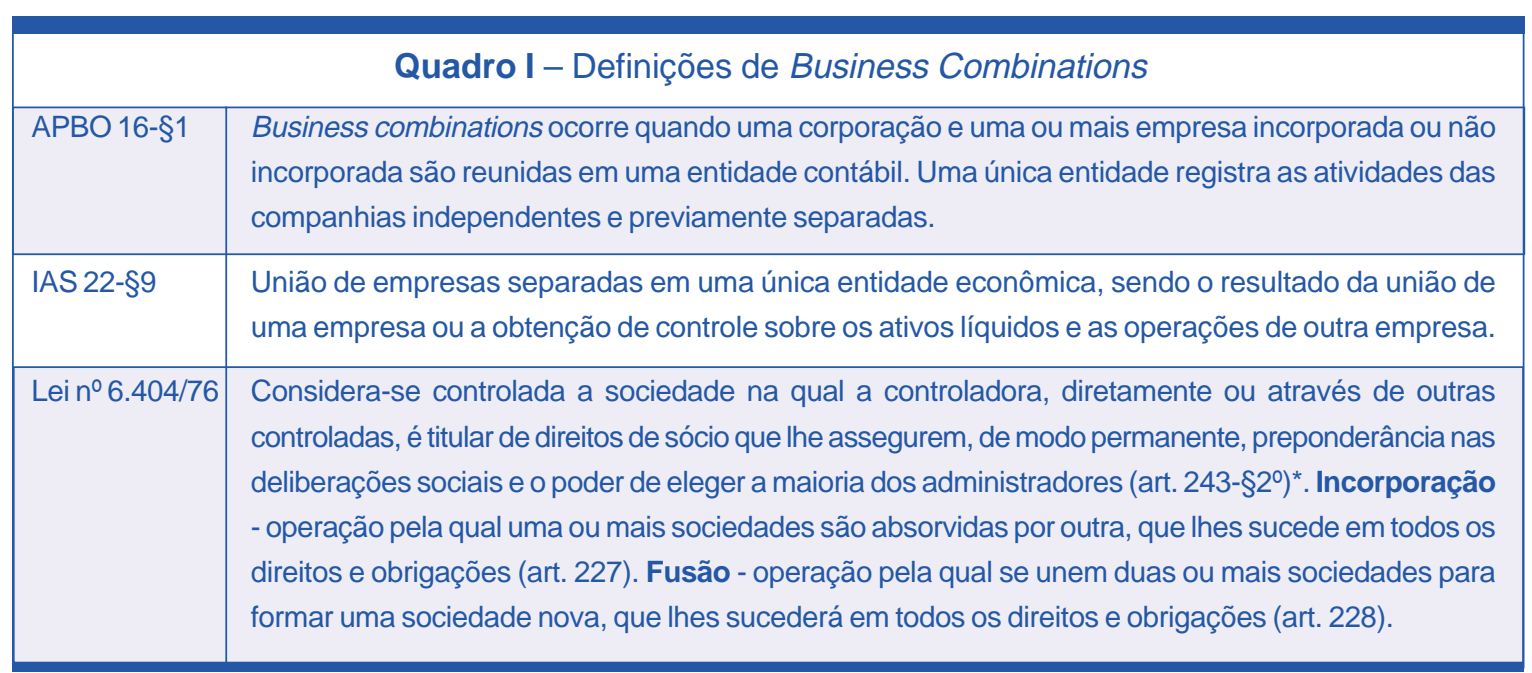

* A Instrução CVM no 247/96 incluiu em seu artigo 3o, inciso I-b, o poder de destituir a maioria dos administradores.

\footnotetext{
${ }^{1}$ Este estudo utiliza a expressão ativos líquidos referindo-se aos ativos adquiridos e passivos assumidos.

${ }^{2}$ Refere-se às operações de fusão, incorporação ou aquisição de controle.
} 
O conceito contábil refletido no parágrafo 1 do Accounting Principles Board Opinion № 16 (APBO 16), enfatiza a união de empresas em uma única entidade contábil (não necessariamente jurídica) e a independência das empresas antes da união. O parágrafo 8 da International Accounting Standard № 22 (IAS 22) ressalta a obtenção de controle.

No Brasil, utiliza-se a expressão "operações de fusões e aquisições" com ou sem a aquisição de controle, o que faz com que não haja similaridade com aqueles conceitos.

A partir das definições apresentadas, este estudo adota a expressão "business combinations" como uma transação econômica em que uma sociedade obtém controle sobre outra, ou quando duas empresas sob controles diferentes se associam (união de empresas) para formar uma terceira, independentemente da forma legal de como o controle é obtido, e da forma resultante da empresa(s) remanescente(s). Portanto, abrange as aquisições de controle, com ou sem as operações de fusão ou incorporação.

Dessa forma, as operações de business combinations são caracterizadas pela obtenção de controle por parte de uma empresa investidora sobre a(s) sociedade(s) investida(s) ou pela efetiva junção de dois grupos independentes. A definição dessas operações tem por base os percentuais de participação em ações ou quotas com direito a voto, não incluindo as ações preferenciais sem direito a voto.

De acordo com o APBO 16-§5 (e para fins deste estudo), o termo business combinations não é utilizado para as seguintes transações:

1) aquisição de parte ou todas as ações da participação minoritária de uma subsidiária; e

2) transferência de ativos líquidos ou a troca de ações entre empresas sob controle comum, tais como entre a controladora e suas subsidiárias ou entre duas subsidiárias da mesma empresa controladora.

No entanto, torna-se necessário evidenciar que, no Brasil, praticamente não existem regras constantes na contabilidade societária a respeito dessas operações. Recentemente, a CVM (Comissão de Valores Mobiliários) emitiu as Instruções no 319/99 e no 320/99, objetivando maior transparência nas operações de incorporação, fusão e cisão. Todavia, um aspecto importante é que a legislação fiscal se antecipou na emissão de normas referentes aos investimentos permanentes. Os termos ágio e deságio foram introduzidos e regulamentados por meio do Decreto-lei $n^{0}$ 1.598/77 de natureza fiscal e não pela Lei $\mathrm{n} \times 6.404 / 76$.

Diante do crescente número de fusões e aquisições, e dos recursos envolvidos, principalmente por parte de empresas estrangeiras (a maioria situada na Europa e nos Estados Unidos) ${ }^{3}$, o tratamento contábil dessas operações é de suma importância. Dessa forma, é mister compreender os pronunciamentos contábeis dos Estados Unidos, também denominados de US-GAAP - Generally Accepted Accounting Principles in the United States, as normas internacionais do IASB - International Accounting Standards Board e as normas contábeis societárias brasileiras.

\section{FORMAS DE BUSINESS COMBINATIONS}

Na reestruturação societária por meio de operações de business combinations, as empresas podem optar por três formas de combinação, quais sejam:

1) Fusão - as empresas combinadas são extintas transferindo seus ativos líquidos para uma nova sociedade constituída pelos acionistas de cada uma das empresas anteriores;

2) Incorporação - a empresa investidora adquire os ativos líquidos de uma (ou mais) sociedade(s) investida(s) por meio de emissão de ações (quando se aplicaria o método "pooling") ou pagamento em moeda corrente e/ou em outros instrumentos de crédito (quando se aplicaria o método "purchase") para os acionistas da(s) investida(s), a(s) qual(is) é(são) extinta(s) pela transferência dos seus ativos líquidos para a investidora;

3) Aquisição de ativos líquidos - as empresas combinadas são mantidas como sociedades legalmente separadas, existindo a relação de participação acionária. A empresa responsável pela combinação (investidora) pode emitir

\footnotetext{
${ }^{3}$ Em novembro de 2000, a Espanha liderava o ranking de investimentos estrangeiros diretos no Brasil. Os Estados Unidos ocupavam o segundo lugar.
} 
ações para os sócios da(s) outra(s) empresa(s), que transferem suas antigas ações para a companhia emissora (quando se aplicaria o método "pooling"), ou pode comprar em moeda corrente e/ou em outros instrumentos de crédito o controle acionário da(s) sociedade(s) investida(s) (quando se aplicaria o método "purchase"). Nesses casos, torna-se necessária a elaboração das demonstrações consolidadas e a transação é reconhecida na conta de Investimentos, evidenciada no balanço patrimonial da investidora.

Essas formas jurídicas de combinação são passíveis de reconhecimento contábil por meio dos métodos pooling e purchase, que serão elucidadas na análise comparativa.

Em seguida, serão apresentadas algumas pesquisas que procuram ressaltar a importância das operações de business combinations no cenário global e, em particular, no Brasil.

\section{DADOS}

O relatório mundial sobre investimentos (World International Report - WIR/98) divulgado pela Conferência das Nações Unidas para o Comércio e Desenvolvimento (UNCTAD) afirma que entre 1992 e 1997 foram realizadas 600 operações de fusões e aquisições no Brasil. Aproximadamente $61 \%$ dos compradores foram investidores externos (principalmente da América do Norte) e $59 \%$ das transações foram de empresas industriais. Em 1997 o volume de investimento externo chegou a US $\$ 16,3$ bilhões, dos quais $63 \%$ (US $\$ 10,269$ bilhões) foram para fusão ou aquisição do controle de companhias brasileiras. ${ }^{4}$

Outro relatório realizado pela KPMG ${ }^{5}$ constata que em 2000 foram realizadas 353 operações de fusões e aquisições no Brasil. Esse número é superior ao do ano de 1999 - que pode ser observado conforme o gráfico seguinte, que apresenta a evolução dessas operações durante o período de 1996 até 2000.

\section{Gráfico 1 - Fusões \& Aquisições}

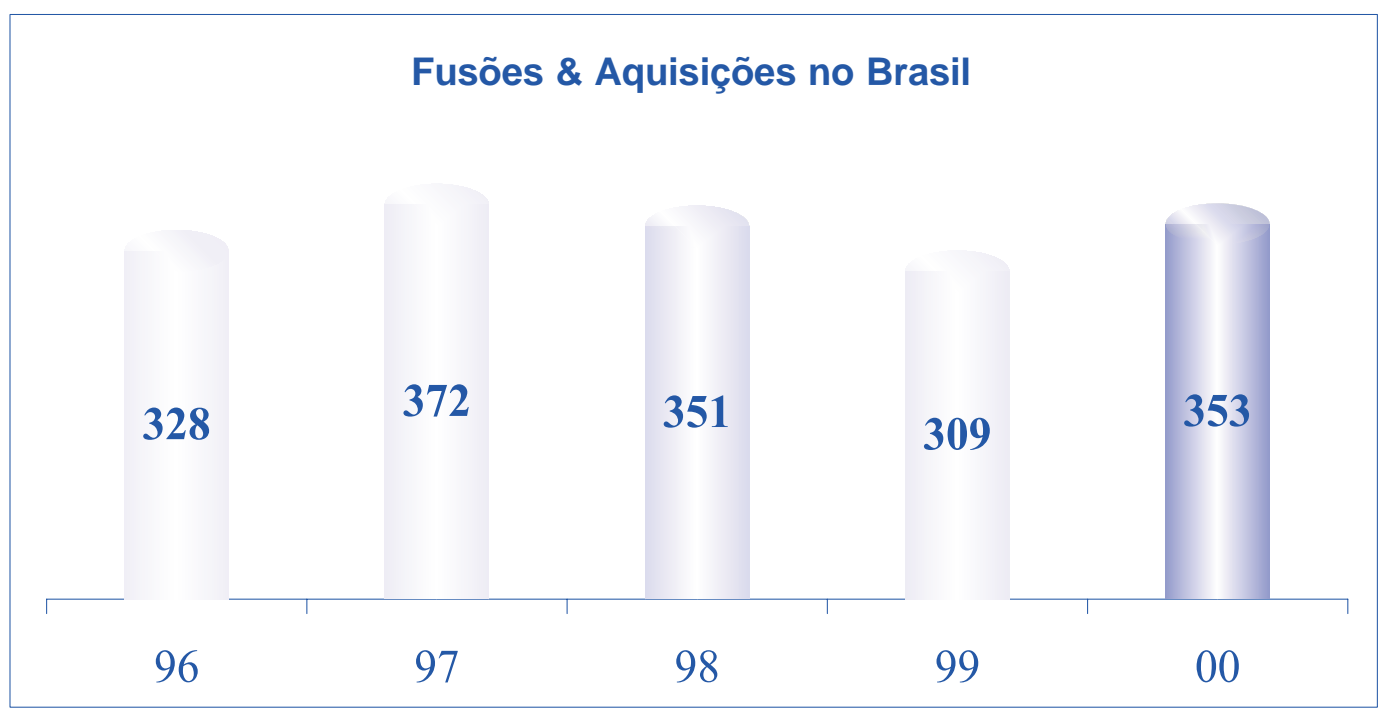

Fonte: KPMG Corporate Finance.

De 1996 até 2000, os setores que mais receberam esse tipo de investimento no Brasil foram o de alimentos, bebidas e fumo, com 184 operações de fusões e aquisições; em segundo lugar, estão as instituições financeiras, com 129; em terceiro, o de telecomunica- ções, com 123; e em quarto, o setor de tecnologia de informação, com 112 transações. O gráfico 2 apresenta essa situação, com destaque dos nove setores econômicos que mais realizaram operações de fusões e aquisições durante os anos de 1996 até 2000.

\footnotetext{
${ }^{4}$ Conforme NEUMANN, Denise. Compra de empresas atrai o investimento externo. Jornal O Estado de São Paulo. São Paulo, 16 de novembro de 1998 , Caderno B, p. 4.

${ }^{5}$ KPMG Corporate Finance. Fusões \& Aquisições. Relatório disponível em: http://www.kpmg.com.br. Acesso: fevereiro de 2000.
} 
Gráfico 2 - Fusões e Aquisições por Setor

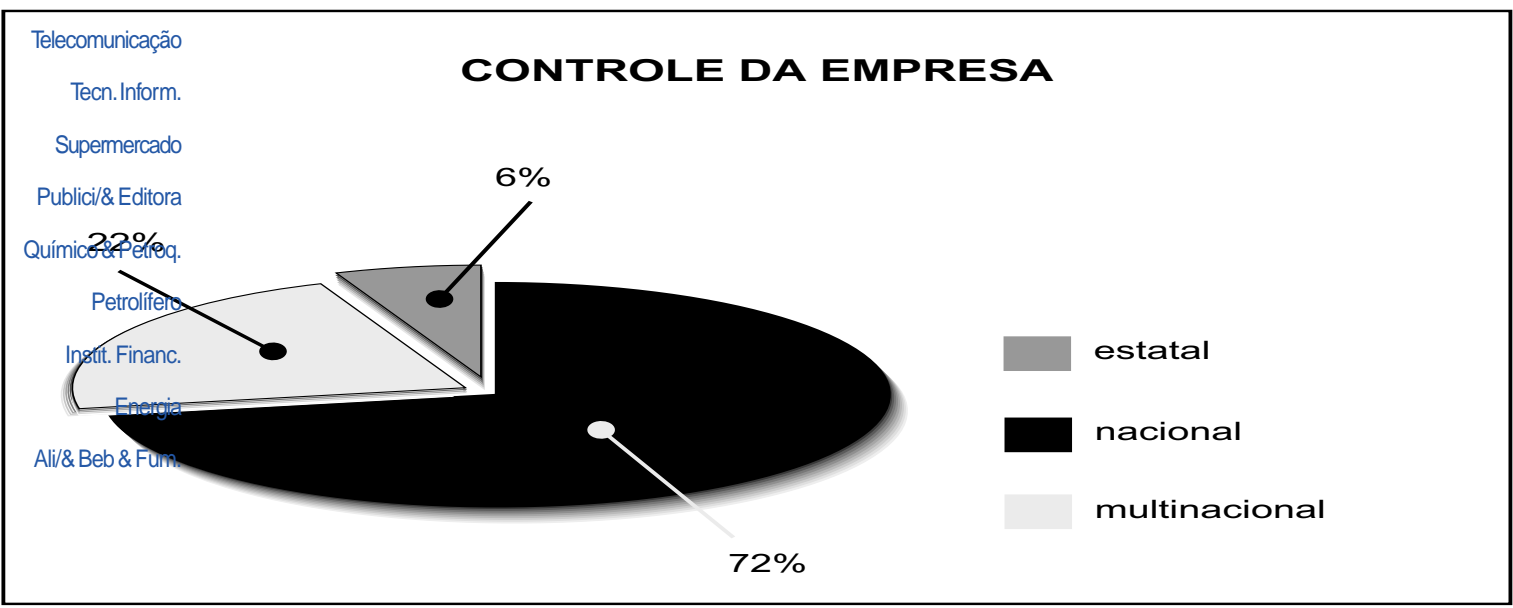

Fonte: KPMG Corporate Finance.

\section{PRINCIPAIS PROBLEMAS}

A harmonização das normas e práticas contábeis tem sido um grande desafio para os normatizadores e profissionais da contabilidade.

Os principais problemas referentes às operações de business combinations, principalmente quando há incorporação ou fusão, dizem respeito ao método apropriado de avaliação e às diferenças nas práticas contábeis, as quais exigem reelaboração das demonstrações contábeis em virtude da(s) entidade(s) resultante(s) da reorganização societária.

O APBO 16 e o IASB abrangem dois métodos para contabilizar as operações de business combinations, enquanto que no Brasil não é prevista, de forma direta, uma denominação específica do método de avaliação. A contabilização dessas transações tem como base o controle da empresa investidora sobre a sociedade investida, sendo, normalmente, necessária a consolidação das demonstrações contábeis.

Diante do exposto, o problema a ser investigado refere-se ao tratamento contábil para as operações de business combinations e às condições para a consolidação ou não das demonstrações contábeis, assim como a identificação de aspectos restritivos para a harmonização das normas e práticas contábeis.

Em face da evolução e complexidade do tema, este estudo irá comparar os principais aspectos refletidos nos pronunciamentos e normas contábeis dos USGAAP, do IASB e do Brasil (BR-GAAP) no que se refere às operações de business combinations e à consolidação das demonstrações contábeis.

\section{ANÁLISE COMPARATIVA}

\section{Normas Contábeis}

Os pronunciamentos e normas contábeis tiveram origem a partir de vários órgãos. O quadro abaixo apresenta as principais organizações envolvidas no desenvolvimento de normas contábeis nos Estados Unidos, na Europa e no Brasil.

Quadro II - Organizações Contábeis

\begin{tabular}{|c|c|c|}
\hline Estados Unidos ${ }^{6}$ & Europa & Brasil \\
\hline $\begin{array}{l}\text { D SEC - Securities and Exchange Commission. } \\
\text { AICPA - American Institute of Certified Public } \\
\text { Accountants. } \\
\text { DASB - Financial Accounting Standards Board. } \\
\text { FASB - Governmental Accounting Standards } \\
\text { Board. } \\
\text { Outras: AAA - American Accounting } \\
\text { Association, IMA - Institute of Management } \\
\text { Accountants etc. }\end{array}$ & $\begin{array}{l}\text { IASB - International Accounting Standards } \\
\text { Committee. } \\
\text { IFAC - Federação Internacional de } \\
\text { Contadores. } \\
\text { I IOSCO - International Organization of } \\
\text { Securities Commissioners. Essa organiza- } \\
\text { ção tem o apoio da SEC e também estuda a } \\
\text { harmonização contábil universal por meio da } \\
\text { aceitação das normas internacionais. }\end{array}$ & $\begin{array}{l}\text { D CVM - Comissão de } \\
\text { Valores Mobiliários. } \\
\text { BACEN - Banco Central } \\
\text { do Brasil } \\
\text { IBRACON - Instituto } \\
\text { Brasileiro de Contado- } \\
\text { res. } \\
\text { CFC - Conselho Federal } \\
\text { de Contabilidade. }\end{array}$ \\
\hline
\end{tabular}

${ }^{6}$ Conforme KIESO, Donald E. \& WEYGANDT, Jerry J. Intermediate Accounting. 9a ed. New York: Wiley, 1998, p. 1-20. 
Os principais pronunciamentos contábeis contidos nos US-GAAP e normas contábeis do IASB e do Bra- sil referentes ao tema são evidenciados no quadros seguintes.

Quadro III - Pronunciamentos e Normas de Business Combinations

\begin{tabular}{|c|c|c|}
\hline US-GAAP & IASB & BR-GAAP \\
\hline $\begin{array}{c}\text { APBO 16, Business Combinations, } \\
\text { emitido em agosto de 1970. }\end{array}$ & $\begin{array}{c}\text { IAS 22, Business Combinations, } \\
\text { revisado em 1998. }\end{array}$ & Lei no 6.404, emitida em dezembro de 1976. \\
\hline $\begin{array}{c}\text { APBO 17, Intangible Assets, } \\
\text { emitido em outubro de 1970. }\end{array}$ & - & $\begin{array}{c}\text { Instrução CVM no 247 emitida em março de 1996, } \\
\text { que dispõe sobre a avaliação de investimentos } \\
\text { em coligadas e controladas. }\end{array}$ \\
\hline $\begin{array}{c}\text { AIN-APBO 16, Business Combinations, } \\
\text { emitido em março de 1973. }\end{array}$ & - & $\begin{array}{c}\text { Instrução CVM no 285, emitida em julho de 1998, } \\
\text { que altera o artigo 14 da Instrução CVM no 247. }\end{array}$ \\
\hline $\begin{array}{c}\text { AIN-APBO 17, Intangible Assets, } \\
\text { emitidas as Interpretações no 1 em abril de } \\
\text { 1972 e no 2 em março de 1973. }\end{array}$ & - & $\begin{array}{c}\text { Instruções CVM no 319 e no } 320 \text { de dezembro de } \\
\text { 1999, que dispõem sobre as operações de } \\
\text { Incorporação, Fusão e Cisão. }\end{array}$ \\
\hline $\begin{array}{c}\text { SFAS 141, Business Combinations, } \\
\text { emitido em 30 de junho de 2001. }\end{array}$ & - & $\begin{array}{c}\text { Instrução CVM no 349 de 6 de março de 2001, } \\
\text { que dispõe sobre as operações de Incorporação, } \\
\text { Fusão e Cisão. }\end{array}$ \\
\hline $\begin{array}{c}\text { SFAS 142, Goodwill and Other Intangible } \\
\text { Assets, emitido em 30 de junho de 2001. }\end{array}$ & - & \\
\hline
\end{tabular}

Quadro IV - Normas de Consolidação

\begin{tabular}{|c|c|c|}
\hline US-GAAP & IASB & BR-GAAP \\
\hline $\begin{array}{c}\text { ARB 51, Consolidated } \\
\text { Financial Statements, emitido } \\
\text { em agosto de 1959. }\end{array}$ & $\begin{array}{c}\text { IAS 27, Consolidated Financial Statements } \\
\text { and Accounting for Investments in } \\
\text { Subsidiaries, revisada em 1994. }\end{array}$ & Lei no 6.404, emitida em dezembro de 1976. \\
\hline $\begin{array}{c}\text { FAS 94, Consolidation of All } \\
\text { Majority-Owned Subsidiaries, } \\
\text { emitido em outubro de 1987. }\end{array}$ & - & $\begin{array}{c}\text { Instrução CVM no 247 emitida em março de 1996, que } \\
\text { também dispõe sobre os procedimentos para elabo- } \\
\text { ração e divulgação das demonstrações consolidadas. }\end{array}$ \\
\hline
\end{tabular}

De um lado, torna-se importante ressaltar que, em agosto de 1996, o FASB iniciou um projeto visando alterar o APBO 16 e APBO 17. Em conseqüência, foram emitidos dois novos pronunciamentos ${ }^{7}$ sobre business combinations e ativos intangíveis em junho de 2001. São estabelecidas significativas alterações para o tratamento contábil do goodwill adquirido e de outros ativos intangíveis, bem como a implementação de um único método de avaliação para as operações de business combinations: o purchase.

Por outro lado, o IASB iniciou a regulamentação das operações de business combinations em novembro de 1983 por meio da norma International Accounting Standard - IAS 22 - com o título "Accounting for Business Combinations". Atualmen- te, o IASB desenvolve um projeto para promover alterações da norma IAS 22.

Com o decorrer do tempo a norma foi revisada três vezes: em dezembro de 1993, outubro de 1996 e julho de 1998, mudando o título para Business Combinations.

No Brasil, existe uma evidenciação diferente dos investimentos permanentes em outras sociedades que não consta nas determinações internacionais. Conforme a Lei $n^{\circ} 6.404$, os investimentos permanentes em sociedades coligadas e controladas são classificados como sub-grupo do ativo permanente. Ressalta-se que, de acordo com os US-GAAP e IASB, o ativo é classificado em apenas dois sub-grupos: corrente/circulante e não corrente/não circulante.

A Lei societária brasileira autoriza a CVM a expe-

\footnotetext{
${ }^{7}$ Vide item FASB e Novo Tratamento Contábil.
} 
dir normas sobre as sociedades cujas demonstrações são abrangidas na consolidação, sendo que o processo de regulamentação dos investimentos permanentes iniciou-se com as Instruções no 1 de 1978 e no 15 de 1980.

Atualmente, a CVM ampliou a evidenciação das operações de fusões e aquisições, por meio das Instruções no 319 e no 320 de dezembro de 1999 e no 349 de março de 2001. Estas abordam o tratamento contábil e, especificamente, a transparência e os critérios contábeis adotados em relação aos acionistas não controladores.

\section{Investimentos em Participações Societárias no Capital Votante}

O quadro seguinte pode ser utilizado como base inicial para a análise da classificação dos investimentos em participações societárias com direito a voto.

Conforme os dados do quadro $\mathrm{V}$, observa-se que, de acordo com os US-GAAP e IASB, os investimentos de curto e longo prazo em equity securities, representados por participações societárias menores que $20 \%$ nas ações ou quotas com direito a voto e quando não existe influência significativa, são avaliados pelo valor de mercado, quando esse for prontamente identificável, ou custo. No Brasil a base de avaliação também é o valor de mercado ou custo; porém, dos dois o menor.

\begin{tabular}{|c|c|c|c|c|}
\hline \multirow{2}{*}{\multicolumn{5}{|c|}{$\begin{array}{r}\text { Quadro V - Investimentos em Participações } \\
\text { US-GAAP }\end{array}$}} \\
\hline & & & & \\
\hline $\begin{array}{l}\text { Participação } \\
\text { Societária no } \\
\text { Capital Votante }\end{array}$ & $\begin{array}{l}\text { Nível de } \\
\text { Influência } \\
\text { Econômica }\end{array}$ & $\begin{array}{c}\text { Tipo de } \\
\text { Investimento }\end{array}$ & $\begin{array}{l}\text { Método de } \\
\text { Avaliação }\end{array}$ & $\begin{array}{l}\text { Apresentação } \\
\text { no Balanço } \\
\text { Patrimonial }\end{array}$ \\
\hline $0 \%-20 \%$ & $\begin{array}{c}\text { Nenhuma ou } \\
\text { Pequena Influência }\end{array}$ & $\begin{array}{l}\text { Temporário de Curto ou } \\
\text { Longo Prazo (CP/LP) }\end{array}$ & Fair Value ou Custo & $\begin{array}{l}\text { Investimentos } \\
\text { de CP ou LP }\end{array}$ \\
\hline $0 \%-20 \%$ & $\begin{array}{l}\text { Influência } \\
\text { Significativa }\end{array}$ & Investida & $\begin{array}{l}\text { MEP - Método da } \\
\text { Equivalência Patrimonial }\end{array}$ & $\begin{array}{l}\text { Investimentos } \\
\text { de CP ou LP }\end{array}$ \\
\hline $20 \%|-| 50 \%$ & $\begin{array}{l}\text { Influência } \\
\text { Significativa }\end{array}$ & Investida & MEP & Investimentos de LP \\
\hline $50 \%-100 \%$ & Controle & Subsidiária & Consolidação & Demonstrações Consolidadas \\
\hline \multicolumn{5}{|c|}{ IASB } \\
\hline $0 \%-20 \%$ & $\begin{array}{c}\text { Nenhuma ou } \\
\text { Pequena Influência }\end{array}$ & $\begin{array}{l}\text { Temporário de Curto/ } \\
\text { Longo Prazo }\end{array}$ & Fair Value ou Custo & $\begin{array}{l}\text { Investimentos } \\
\text { de CP ou LP }\end{array}$ \\
\hline $20 \%|-| 50 \%$ & $\begin{array}{l}\text { Influência } \\
\text { Significativa }\end{array}$ & Associada & $\begin{array}{l}\text { MEP ou Custo ou Custo ou } \\
\text { Valor Reavaliado }\end{array}$ & Investimentos de LP \\
\hline $50 \%-100 \%$ & Controle & Subsidiária & Consolidação & Demonstrações Consolidadas \\
\hline $90 \% \mid-100 \%$ & Controle & $\begin{array}{c}\text { Subsidiária Virtualmente } \\
\text { Integral }\end{array}$ & Consolidação ou Não & $\begin{array}{l}\text { Demonstrações } \\
\text { Consolidadas ou Não }\end{array}$ \\
\hline $100 \%$ & Controle & Subsidiária Integral & Consolidação ou Não & $\begin{array}{c}\text { Demonstrações } \\
\text { Consolidação ou Não }\end{array}$ \\
\hline \multicolumn{5}{|c|}{ BR-GAAP } \\
\hline $0 \%-10 \%{ }^{*}$ & $\begin{array}{c}\text { Nenhuma ou } \\
\text { Pequena Influência }\end{array}$ & $\begin{array}{c}\text { Temporário de Curto ou } \\
\text { Longo Prazo }\end{array}$ & Custo ou Valor de Mercado & Investimentos de CP ou LP \\
\hline $\begin{array}{l}10 \%|-| 50 \% * \\
{ }^{*} \text { capital social }\end{array}$ & $\begin{array}{l}\text { Influência } \\
\text { Significativa }\end{array}$ & Coligada & MEP & Investimentos Permanentes \\
\hline $50 \%-\mid 100 \%$ & Controle & Controlada & Consolidação & Demonstrações Consolidadas \\
\hline
\end{tabular}

Os US-GAAP e o IASB determinam, de forma inicial, a classificação dos investimentos societários com influência significativa com base no percentual de participação na sociedade investida/associada de $20 \%$ no capital votante, enquanto que no Brasil é de $10 \%$ no capital social 
e que este tipo de investimento é denominado de coligada, e abrange as participações societárias com e sem direito a voto.

A legislação societária brasileira considera controlada a sociedade na qual a investidora, direta ou indiretamente, seja titular de direitos de sócio que lhe assegurem, de modo permanente, a preponderância nas deliberações sociais e o poder de eleger ou destituir a maioria dos administradores. Entretanto, os US-GAAP exigem a participação de mais de $50 \%$ no capital votante para as sociedades controladas, enquanto que o IASB estabelece o poder de dirigir as políticas operacionais e financeiras de uma empresa, com o objetivo de obter benefícios decorrentes de suas atividades.
O Brasil, em consonância com o IASB, enfatizam a obtenção de controle por meio da preponderância nas deliberações sociais e do poder de eleger ou destituir a maioria dos administradores.

Outra forma de obtenção de controle, obtido com metade ou menos do capital votante, refere-se ao acordo de acionistas. Embora não esteja apresentado no Quadro V, os US-GAAP, IASB e BR-GAAP prevêem a obtenção de controle por meio desta forma jurídica.

\section{Termos}

Visando melhor entendimento, são apresentados os principais termos referentes ao tema, conforme os pronunciamentos e normas contábeis analisados.

\begin{tabular}{|c|c|c|}
\hline \multicolumn{3}{|c|}{ Quadro VI - Termos } \\
\hline BR-GAAP & US-GAAP & IASB \\
\hline Ágio & Goodwill & Goodwill \\
\hline Aquisição & Acquisition & Acquisition \\
\hline Fusões \& Aquisições & Business combinations & Business combinations \\
\hline- & Pooling of interests method & Pooling of interests method \\
\hline- & Purchase method & Purchase method \\
\hline- & - & Uniting of interests \\
\hline Ativos líquidos & Net assets & Net assets \\
\hline Coligada & Investee & Associate \\
\hline Controlada & Subsidiary & Subsidiary \\
\hline Controle & Control & Control \\
\hline Demonstrações contábeis consolidadas & Consolidated financial statements & Consolidated financial statements \\
\hline Deságio & Negative goodwill / Deferred credit & Negative goodwill \\
\hline Fusão & Consolidation / Merger & Merger \\
\hline Incorporação & Merger & Merger \\
\hline
\end{tabular}

No Brasil, os termos ágio e deságio referem-se à diferença entre custo de aquisição pago pela investidora e o valor contábil da investida. Porém, essa diferença pode estar relacionada ao: a) excesso entre o valor de mercado e o valor contábil dos ativos líquidos; e/ou b) excesso entre o valor pago e o valor de mercado.

Para fins deste estudo, os termos ágio e deságio abrangem uma figura equivalente ao goodwill e goodwill negativo e representam a diferença entre o valor excedente pago pela investidora em relação ao valor de mercado dos ativos líquidos da investida, tendo como fundamento econômico a expectativa de resultados futuros. Nesse sentido, o ágio pago decorrente da diferença entre o valor pago e o valor de mercado representa o verdadeiro goodwill da sociedade investida.

\section{Tratamento Contábil}

Até junho de 2001, os US-GAAP estabeleciam dois métodos contábeis para contabilizar as operações de business combinations: purchase ou pooling of interests; da mesma forma que atualmente o IASB determina. No entanto, existe nos Estados Unidos um método contábil específico, exigido pela SEC, denominado push-down accounting. No Brasil, como afirmado anteriormente, não existe, de forma explícita, denominação específica dos métodos de avaliação para as operações de fusão, incorporação e aquisição de controle; entretanto, essas transações podem ser avaliadas pelo valor contábil ou valor de mercado. O quadro seguinte resume essas observações. 


\begin{tabular}{|c|c|c|}
\hline \multicolumn{3}{|c|}{ Quadro VII - Métodos de Avaliação } \\
\hline BR-GAAP & US-GAAP & IASB \\
\hline Valor Contábil & Pooling & Pooling \\
\hline Valor de Mercado & Purchase & \\
\hline & Push-Down Accounting (SEC) \\
\hline
\end{tabular}

A legislação societária brasileira e a Instrução CVM no 247 tratam dos investimentos em sociedades controladas, enfocando a apresentação desses investimentos nas demonstrações contábeis individuais da investidora e exigem a elaboração e divulgação da consolidação para um número restrito de empresas controladoras.

O investimento permanente de companhia aberta em coligadas, suas equiparadas e em controladas devem ser avaliados pelo método de equivalência patrimonial nas demonstrações contábeis individuais da investidora. A equivalência patrimonial corresponde ao valor do investimento determinado mediante a aplicação de porcentagem de participação no capital so- cial sobre o patrimônio líquido de cada coligada, sua equiparada e controlada. ${ }^{8}$

A avaliação dos investimentos permanentes em sociedades controladas e, inclusive, coligadas deverá ser realizada pelo custo de aquisição, sendo constituída uma provisão para perdas comprovadamente permanentes. Não é permitida modificação do valor do investimento em razão de recebimento sem custo de ações ou quotas bonificadas.

A CVM ${ }^{9}$ determina que o valor contábil do investimento abranja o custo de aquisição mais a equivalência patrimonial e o ágio não amortizado, deduzido do deságio não amortizado e da provisão para perdas, conforme o quadro seguinte:

\begin{tabular}{|c|}
\hline Quadro VIII - BR-GAAP: Valor Contábil do Investimento \\
\hline Valor da Equivalência Patrimonial \\
\hline (+)Ágio não amortizado \\
\hline (-) Deságio não amortizado \\
\hline (-) Provisão para Perdas \\
\hline (=) Valor Contábil do Investimento \\
\hline
\end{tabular}

Em relação à contabilização da compra de participações societárias, de acordo com o artigo 13 da Instrução CVM nำ247, o custo de aquisição deve ser desdobrado em duas sub-contas:

(1) equivalência patrimonial- referindo-se à parcela de participação no capital social sobre o patrimônio líquido adquirido, com base no valor contábil da investida; e

(2) ágio ou deságio - na aquisição ou na subscrição, que se refere à diferença, para mais ou para menos, respectivamente, entre o custo de aquisição do investimento e a equivalência patrimonial.

\section{Pooling of Interests}

Pode-se constatar ${ }^{10}$ que o método da comunhão de interesses (pooling of interests) foi o mais utilizado para as operações de business combinations nas décadas de trinta a sessenta nos Estados Unidos, embora o termo tenha sido somente aplicado a partir dos anos quarenta.

No início, o método era adotado para as transações em que havia dificuldade na identificação da empresa adquirente; entretanto o AICPA impôs em 1950 novos requisitos e exigiu a manutenção dos acionistas das empresas combinadas para a aceitação desse método. Contudo, as exigências foram flexibilizadas e houve abusos que distorciam a aplicação do pooling. Somente em 1970 foram instituídas restrições mais rígidas com a emissão do APBO 16 e estabeleceu-se doze requisitos diminuindo sua aplicação.

\footnotetext{
${ }^{8}$ Instrução CVM n ${ }^{\circ} 247 / 96$, art. $1^{\circ}$

${ }^{9}$ Instrução CVM nº $247 / 96$, art. $4^{\circ}-\S 2^{\circ}$.

${ }^{10}$ Conforme DELANEY, Patrick R. et alii. GAAP 97 : Interpretation and Application of Generally Accepted Accounting Principles 1997. USA: Wiley, 1997, p. $337-338$
} 
O FASB determinou a eliminação do método pooling por meio da aprovação do novo pronunciamento sobre business combinations em 29 de junho de 2001. A adoção do método purchase para o reconhecimento de todas as business combinations passa a vigorar a partir de julho de 2001. Contudo, o método pooling devia ser aplicado para operações em que ocorria uma troca mútua de ações com direito a voto, sendo que os acionistas mantinham nas entidades combinadas a porcentagem de participação existente antes da combinação. Em essência, devia haver a entrega de todas ou da maioria das ações.

As normas internacionais do IASB utilizam um termo específico denominado "união de interesses" para aplicar o método pooling. Essa união caracteriza-se pela integração dos riscos e benefícios entre as empresas combinadas e somente é realizada em circunstâncias excepcionais em que não é possível identificar a sociedade adquirente.

\section{EXEMPLOS DE BUSINESS COMBINATIONS CONTABILIZADOS PELO POOLING}

O método pooling caracteriza-se, principalmente, pela troca de ações e a manutenção dos valores contábeis das empresas combinadas.

Inicialmente, serão considerados os seguintes balanços patrimoniais das empresas Cia. A e Cia. B a serem combinadas:

\begin{tabular}{|l|c|c|}
\hline \multicolumn{3}{|c|}{ Balanços Iniciais (Em \$) } \\
\hline \multicolumn{2}{|c|}{ Cia. A } & Cia. B \\
\hline Total do Ativo & $\mathbf{1 . 8 0 0}$ & $\mathbf{1 . 2 0 0}$ \\
\hline Patrimônio Líquido & & \\
- Capital: Acionista Antonio & 1.800 & - \\
- Capital: Acionista Berta & - & 1.200 \\
\hline Total do Patrimônio Líquido & $\mathbf{1 . 8 0 0}$ & $\mathbf{1 . 2 0 0}$ \\
\hline
\end{tabular}

As ações da Cia. A e Cia. B pertencem aos acionistas Antonio e Berta, respectivamente. Admite-se que ambas as ações têm valor nominal de $\$ 1,00$ e que na troca de ações é mantida a relação "1 × 1" - cada acionista irá receber as ações de acordo com a partici- pação nas atuais sociedades a serem combinadas.

A seguir, serão exemplificadas as três formas de business combinations contabilizadas pelo pooling.

1) Fusão: Cia. A + Cia. B $\rightarrow$ Cia. C

\begin{tabular}{|ll|ll|}
\hline \multicolumn{3}{|c|}{ Lançamentos pela extinção de cada empresa } \\
\hline \multicolumn{3}{|c|}{ Cia. A } & \multicolumn{2}{c|}{ Cia. B } \\
\hline D - Capital & $\$ 1.800$ & D - Capital & $\$ 1.200$ \\
\hline C - Ativos & $\$ 1.800$ & C - Ativos & $\$ 1.200$ \\
\hline
\end{tabular}

\begin{tabular}{|l|c|}
\hline \multicolumn{2}{|c|}{ Lançamento pela constituição da nova empresa Cia. C } \\
\hline D - Ativos & $\$ 3.000$ \\
\hline C - Capital - referente ao acionista Antonio & $\$ 1.800$ \\
\hline C - Capital - referente à acionista Berta & $\$ 1.200$ \\
\hline
\end{tabular}

\begin{tabular}{|l|c|c|c|}
\hline \multicolumn{4}{|c|}{ Balanços Patrimoniais Antes e Após a Fusão } \\
\hline & Extinta Cia. A & Extinta Cia. B & Nova Cia. C \\
\hline Ativos & 1.800 & 1.200 & 3.000 \\
\hline Total do Ativo & $\mathbf{1 . 8 0 0}$ & $\mathbf{1 . 2 0 0}$ & $\mathbf{3 . 0 0 0}$ \\
\hline Capital - Antonio & 1.800 & - & 1.800 \\
\hline Capital - Berta & - & 1.200 & 1.200 \\
\hline Total do Passivo & $\mathbf{1 . 8 0 0}$ & $\mathbf{1 . 2 0 0}$ & $\mathbf{3 . 0 0 0}$ \\
\hline
\end{tabular}


A empresa resultante da fusão, Cia. C, emite ações para os acionistas das companhias combinadas pelo valor contábil $(\$ 1,00)$ e registra os ativos líquidos de acordo com os respectivos valores contábeis das extintas Cia. A e Cia. B. Portanto, os valores contábeis das companhias são mantidos e as participações acionárias de Antonio e Berta permanecem inalteradas, sendo respectivamente de $60 \%$ e $40 \%$.

Caso a emissão das ações seja efetuada por um valor nominal diferente do valor contábil, torna-se necessária a equabilidade de acordo com o número de ações entregues aos acionistas, respeitando suas respectivas participações acionárias nas empresas extintas.
2) Incorporação: Cia. A + Cia. B $\rightarrow$ Cia. A

A Cia. A (Antonio) emite 1.200 novas ações para a proprietária da Cia. B (Berta) e a Cia. B é extinta, transferindo seus ativos líquidos para a Cia. A.

\begin{tabular}{|ll|}
\hline \multicolumn{2}{|c|}{ Lançamento - Cia. A } \\
\hline D - Ativos & $\$ 1.200$ \\
\hline C - Capital - acionista Berta & $\$ 1.200$ \\
\hline
\end{tabular}

\begin{tabular}{|lc|}
\hline \multicolumn{2}{|c|}{ Lançamento pela Extinção da Cia. B } \\
\hline D - Capital & $\$ 1.200$ \\
\hline C - Ativos & $\$ 1.200$ \\
\hline
\end{tabular}

\begin{tabular}{|l|c|c|c|}
\hline \multicolumn{4}{|c|}{ Balanços Patrimoniais Antes e Após a Incorporação } \\
\hline & $\begin{array}{c}\text { Cia. A } \\
\text { Antes }\end{array}$ & $\begin{array}{c}\text { Extinta } \\
\text { Cia. B }\end{array}$ & $\begin{array}{c}\text { Cia. A } \\
\text { Após }\end{array}$ \\
\hline Ativos & 1.800 & 1.200 & 3.000 \\
\hline Total do Ativo & $\mathbf{1 . 8 0 0}$ & $\mathbf{1 . 2 0 0}$ & $\mathbf{3 . 0 0 0}$ \\
\hline Capital - Antonio & 1.800 & - & 1.800 \\
\hline Capital - Berta & - & 1.200 & 1.200 \\
\hline Total do Passivo & $\mathbf{1 . 8 0 0}$ & $\mathbf{1 . 2 0 0}$ & $\mathbf{3 . 0 0 0}$ \\
\hline
\end{tabular}

De acordo com o demonstrativo acima, pode-se verificar que a Cia. A adquiriu por meio de incorporação $100 \%$ dos ativos da Cia. B. Após a incorporação, a Cia. A é de propriedade de Antonio, com $60 \%$, e de Berta com 40\%.
3) Aquisição: Cia. A + Cia. B $\rightarrow$ Cia. A + Cia. B A Cia. A é responsável pela combinação com a Cia. B e emite 1.200 novas ações, que são entregues à acionista Berta da Cia. B. Por outro lado, Berta transfere as suas ações da Cia. B para a Cia. A.

\begin{tabular}{|c|c|c|c|}
\hline \multicolumn{4}{|c|}{ Lançamentos pela Aquisição e Troca de Ações } \\
\hline \multicolumn{2}{|c|}{ Cia. A } & \multicolumn{2}{|l|}{ Cia. B } \\
\hline D - Investimentos & $\$ 1.200$ & D - Capital: Berta & $\$ 1.200$ \\
\hline C - Capital: Berta & $\$ 1.200$ & C - Capital: Cia. A & $\$ 1.200$ \\
\hline
\end{tabular}

\begin{tabular}{|c|c|c|c|c|c|}
\hline \multicolumn{6}{|c|}{ Balanços Patrimoniais Antes e Após a Aquisição } \\
\hline & \multirow{2}{*}{$\begin{array}{l}\text { Cia. A } \\
\text { Após }\end{array}$} & \multirow{2}{*}{$\begin{array}{c}\text { Cia. B } \\
\text { Antes e Após }\end{array}$} & \multicolumn{2}{|c|}{ Eliminações } & \multirow{2}{*}{$\begin{array}{l}\text { Consolidado } \\
\text { Após }\end{array}$} \\
\hline & & & Débito & Crédito & \\
\hline Ativos & 1.800 & 1.200 & & & 3.000 \\
\hline Investimentos - Cia. B & 1.200 & & & 1.200 & - \\
\hline Total do Ativo & 3.000 & 1.200 & & & 3.000 \\
\hline Capital - Antonio & 1.800 & - & & & 1.800 \\
\hline Capital - Berta & 1.200 & & & & 1.200 \\
\hline Capital - Cia. A & - & 1.200 & 1.200 & & - \\
\hline Total do Passivo & 3.000 & 1.200 & & & 3.000 \\
\hline
\end{tabular}


Neste caso, somente é realizada a consolidação pró-forma das demonstrações contábeis para fins de divulgação. Entretanto, nas demonstrações contábeis individuais, a investidora reconhece a transação na linha investimentos do balanço patrimonial, enquanto que a investida reconhece a transferência do capital acionário.

Por meio desse exemplo foi possível verificar as formas de business combinations contabilizadas de acordo com o pooling. A participação acionária de cada empresa, antes e depois da combinação, foi mantida por meio da emissão e transferência de ações com direito a voto. Contudo, torna-se importante lembrar que as sociedades deviam atender aos requisitos, exigidos pelo APBO 16 até junho de 2001, ou condições estabelecidas pelo IASB para a aplicação do pooling.

Admitindo-se apenas os balanços patrimoniais $\mathrm{da}(\mathrm{s})$ empresa(s) remanescente(s), temos as seguintes demonstrações:

\begin{tabular}{|l|c|c|c|}
\hline \multicolumn{4}{|c|}{ Balanços Patrimoniais Após a Operação de Business } \\
\hline Operação & $\begin{array}{c}\text { Fusão } \\
\text { Cia. A }\end{array}$ & $\begin{array}{c}\text { Incorporação } \\
\text { Cia. B }\end{array}$ & $\begin{array}{c}\text { Aquisiçãons } \\
\text { Consolidado }\end{array}$ \\
\hline Ativos & 3.000 & 3.000 & 3.000 \\
Investimentos - Cia. B & - & - & - \\
Total do Ativo & 3.000 & 3.000 & 3.000 \\
Capital - Antonio & 1.800 & 1.800 & 1.800 \\
Capital - Berta & 1.200 & 1.200 & 1.200 \\
Capital - Cia. A & - & - & - \\
Total do Passivo & 3.000 & 3.000 & 3.000 \\
\hline
\end{tabular}

Podemos constatar que o balanço patrimonial permanece inalterado nas três operações de business combinations. Isso ocorre, exclusivamente, porque houve a manutenção dos valores contábeis.

A única alteração refere-se à forma jurídica da(s) empresa(s) remanescente, ou seja, de como a reorganização societária foi planejada. Na fusão, surge uma nova companhia. $\mathrm{Na}$ incorporação, a empresa incorporadora/adquirente é mantida. Na aquisição, as empresas são mantidas e realiza-se a consolidação pró-forma das demonstrações contábeis.

\section{Requisitos Básicos do Pooling}

Segundo o APBO 16, parágrafos 45 ao 48, para que a operação seja reconhecida como pooling, devese atender integralmente a 12 requisitos, que podem ser divididos em três categorias, quais sejam:

I - Atributos das empresas combinadas;

II - Forma de combinação; e

III - Ausência de transações planejadas para articular o pooling (demonstração de que a combinação não foi planejada de forma intencional).

O IASB afirma que a integração dos riscos e benefícios é possível pela troca equalizada das ações com direito a voto, resultando na manutenção dos direitos dos acionistas das sociedades previamente separadas. As condições estabelecidas para a divisão mútua dos riscos e benefícios são:

a) a substancial maioria, se não todas, das ações com direito a voto das empresas combinadas são trocadas ou combinadas;

b) o valor de mercado de uma empresa não é significativamente diferente da outra companhia;

c) os acionistas de cada empresa mantêm, de forma substancial, os mesmos direitos na(s) empresa(s) resultante da combinação, em relação aos direitos possuídos antes da combinação.

\section{TRATAMENTO DO POOLING EM RELAÇÃO AO PATRIMÔNIO LÍQUIDO}

No pooling, a(s) empresa(s) resultante(s) da combinação (fusão, incorporação ou aquisição por troca de ações) contabiliza(m) os ativos líquidos de acordo com os valores contábeis dos respectivos ativos e passivos das empresas combinadas e anteriormente separadas. O capital social da(s) empresa(s) remanescente(s) deve ser igual ao valor nominal ou valor declarado das ações em circulação. Geralmente, a reserva de ágio e os lucros ou prejuízos acumu- 
lados são iguais à soma dos respectivos valores das empresas combinadas.

Entretanto, torna-se necessário o ajuste das contas do patrimônio líquido quando o valor nominal ou declarado das ações for superior ao capital integralizado (paid-in capital) das empresas combinadas, a fim de que a participação dos acionistas das empresas antes da combinação seja a mesma na(s) empresa(s) remanescente(s).

O conceito básico, apresentado no APBO 16, pode ser sintetizado por meio dos seguintes procedimentos:

1) quando houver diferença positiva entre o valor do capital contribuído da(s) empresa(s) investida(s) e o valor das ações emitidas, deve-se contabilizar esta diferença como reserva de ágio.

2) quando houver diferença negativa entre o valor do capital contribuído da(s) empresa(s) investida(s) e o valor das ações emitidas, devese seguir uma ordem para redução das contas em função do valor da diferença. Inicialmente, deve-se reduzir a reserva de ágio da(s) investida(s), em seguida a reserva de ágio da empresa emissora e, se necessário, diminuir as contas de lucros acumulados, iniciando-se pelo saldo da(s) empresa(s) investida(s).

PURCHASE

De acordo com os US-GAAP, o método da compra (purchase) devia ser adotado para todas as operações de business combinations que não cumpriam os doze requisitos estabelecidos para a aplicação do pooling; todavia, a partir de primeiro de julho de 2001, é adotado para todas as operações de business combinations.

O IASB estabelece o purchase para todas as transações que não atendem às três condições necessárias para a união de interesses e impõe a identificação dos acionistas da sociedade compradora ou investidora ou controladora e os da companhia investida ou controlada.

Esse método tem como principal característica o pagamento pela aquisição de uma empresa em moeda corrente, podendo também ser efetuado com a emissão de ações ou títulos de dívida. Portanto, não existe, de forma plena, a troca de ações com direito a voto.

O parâmetro básico para o reconhecimento dos ativos líquidos da sociedade investida é o fair value (valor de mercado) dos ativos e passivos, pois representa o preço efetivo pago (medido individualmente) pelo ativo adquirido ou passivo assumido. Dessa forma, o valor pago pelo investimento demonstra quanto o comprador pagaria pelo ativo ou passivo no mercado e a quantia paga a mais (goodwill) por adquirir em uma só transação a totalidade dos ativos líquidos.

A contabilização das operações, também denominadas de purchase business combinations, abrange três etapas:

1) determinar o valor pago;

2) calcular a diferença entre o valor pago e o valor contábil do investimento, alocando o custo identificável para os ativos líquidos na base do respectivo valor de mercado na data da aquisição; e

3) reconhecer o goodwill ou o goodwill negativo em função da diferença entre o valor pago e o valor de mercado dos ativos adquiridos e passivos assumidos.

\section{DIFERENÇA EM RELAÇÃO AO VALOR CONTÁBIL DO INVESTIMENTO}

O valor pago pelo investimento pode ser diferente do valor contábil. Caso a diferença seja devido ao valor de mercado dos ativos líquidos, essa deve ser alocada de acordo com o valor de mercado dos respectivos ativos e passivos na data efetiva da aquisição. Se após a realização da alocação ainda houver algum saldo remanescente da diferença, esse valor deverá ser reconhecido como goodwill ou goodwill negativo.

\section{GOODWILL E GOODWILL NEGATIVO}

O goodwill decorrente de uma aquisição refere-se à diferença positiva entre o valor pago e o valor de mercado dos ativos líquidos, devendo ter fundamento econômico com base em expectativas de benefícios futuros. De acordo com APBO 16, logo após o reconhecimento do goodwill, esse devia ser amortizado como despesa, numa base sistemática, de acordo com o período de benefício estimado, não devendo exceder a 40 anos.

O goodwill negativo decorre da diferença negativa, e seguia um procedimento específico. Inicialmente, os valores dos ativos não circulantes, com exceção dos títulos e valores mobiliários de longo prazo, deviam ser reduzidos. Se houver mais de um ativo não circulante 
sujeito a redução, essa devia ser proporcional ao valor de mercado desses ativos. Caso sejam reduzidos a zero e ainda haja alguma diferença residual entre o valor pago e o valor de mercado, o valor residual devia ser reconhecido como crédito diferido (deferred credit), sendo também amortizado, de forma sistemática, considerando-se o período estimado de benefício de até 40 anos. ${ }^{11}$

A norma IAS 22 do IASB inclui aspectos específicos, em especial para o reconhecimento do goodwill, goodwill negativo e do processo de amortização. $O$ goodwill refere-se à diferença entre o custo de aquisição e o valor de mercado dos ativos e passivos adquiridos. A investidora reconhece o goodwill provindo da aquisição como um ativo, representando um pagamento feito como antecipação de benefícios futuros, sendo amortizado em uma base sistemática, de acordo com a vida útil estimada. O período de amortização deve refletir a melhor estimativa do período em que os benefícios econômicos serão obtidos pela empresa, não devendo exceder a 20 anos. Entretanto, esse período pode ser ampliado, sendo necessárias as justificativas.

O IASB ${ }^{12}$ exige que o goodwill negativo seja apresentado como uma dedução do goodwill (positivo), sendo reconhecido como receita de acordo com:

1) expectativas de despesas e prejuízos futuros mensurados com confiabilidade, identificados no plano de aquisição da empresa adquirente. Nesse caso, a parcela do goodwill negativo deve ser reconhecida como receita, na medida em que ocorrerem os prejuízos. Caso esses prejuízos e despesas estimados não sejam reconhecidos no período esperado, o goodwill negativo deve ser tratado como a seguir:

2) não expectativa de despesas e prejuízos futuros que podem ser mensurados com confiabilidade na data de aquisição, sendo reconhecidos como receita quando:

- a quantia do goodwill negativo, que não exceder o valor de mercado dos ativos não monetários identificáveis adquiridos, deve ser reconhecida como receita numa base sistemática sobre a vida útil média remanescente dos ativos depreciáveis/amortizáveis adquiridos; e

$\rightarrow$ a quantia do goodwill negativo, que exceder o valor de mercado dos ativos não monetários identificáveis adquiridos, deve ser reconhecida imediatamente como receita.

Esse tratamento atual estabelecido pelo IASB permite que a investidora reconheça o goodwill negativo, imediatamente, como receita e, em conseqüência, registre lucros de forma inadequada.

\section{ÁGIO E DESÁGIO}

O ágio ou deságio surge na investidora no momento da compra de determinada participação societária ou quando adquire uma parcela adicional de participação. Portanto, a subscrição de ações, ainda que por valor acima/abaixo do valor patrimonial da ação, não gera ágio/deságio se for realizada na exata proporção anterior ao aumento de capital.

De acordo com o artigo 14 da Instrução CVM no 247, alterado pela Instrução CVM no 285, o ágio ou o deságio computado na ocasião da aquisição ou subscrição do investimento deverá ser contabilizado com a indicação do fundamento econômico que o determinou. Essas instruções determinam que:

1) o ágio ou deságio decorrente da diferença entre o valor de mercado de parte ou de todos os bens do ativo da coligada e controlada e o respectivo valor contábil deverá ser amortizado na proporção em que o ativo for sendo realizado na coligada e controlada, por depreciação, amortização, exaustão ou baixa em decorrência de alienação ou perecimento desses bens ou do investimento;

2) o ágio ou deságio decorrente da diferença entre o valor pago na aquisição do investimento e o valor de mercado dos ativos e passivos da coligada ou controlada, referido no item anterior, deverá ser amortizado da seguinte forma:

$\Rightarrow$ o ágio ou deságio decorrente de expectativa de resultado futuro deve ser amortizado no prazo não excedente a dez anos, na extensão e proporção dos resultados projetados que o determinaram, ou pela baixa por alienação ou perecimento do investimento. Os resultados projetados devem ser objeto de verificação anual, a fim de que sejam revisados os critérios utilizados para amortização ou registrada a baixa integral do ágio; e

\footnotetext{
${ }^{11}$ Vide item FASB e Novo Tratamento Contábil.

12 De acordo com os parágrafos 59 ao 64 da norma IAS 22, revisada em outubro de 1998.
} 
$\Rightarrow$ o ágio decorrente da aquisição do direito de exploração, concessão ou permissão delegadas pelo Poder Público - no prazo estimado ou contratado de utilização, de vigência ou de perda de substância econômica, ou pela baixa por alienação ou perecimento do investimento.

Caso não exista fundamento econômico, o ágio deve ser reconhecido imediatamente como perda e justificado em nota explicativa, enquanto que o deságio somente é amortizado pela alienação ou perecimento do investimento.

No processo de elaboração das demonstrações contábeis consolidadas, o ágio ou o deságio decor- rente da diferença entre o valor de mercado e o valor contábil é adicionado ou retificado na conta utilizada pela controlada para o registro do respectivo ativo ou passivo.

De forma diferente, o ágio e deságio fundamentados em expectativa de resultados futuros devem estar destacados, respectivamente, no ativo permanente e resultado de exercício futuro.

Uma vez identificados os tratamentos do goodwill/ ágio e do goodwill negativo/deságio estabelecidos pelos pronunciamentos e normas do APBO 16, IASB e Brasil, o quadro seguinte mostra os principais aspectos analisados.

\begin{tabular}{|c|c|c|c|}
\hline \multicolumn{4}{|c|}{ Quadro IX - Goodwill/Ágio e Goodwill Negativo/ Deságio } \\
\hline \multicolumn{4}{|c|}{ Goodwill/Ágio } \\
\hline & APBO 16 & IASB & BR-GAAP \\
\hline Definição & $\begin{array}{c}\text { Excesso do Valor Pago } \\
\text { sobre o Fair Value }\end{array}$ & $\begin{array}{l}\text { Excesso do Valor Pago } \\
\text { sobre o Fair Value }\end{array}$ & $\begin{array}{l}\text { Excesso do Valor Pago } \\
\text { sobre o Valor de Mercado }\end{array}$ \\
\hline Fundamento & $\begin{array}{l}\text { Expectativa de } \\
\text { Lucros Futuros }\end{array}$ & $\begin{array}{l}\text { Expectativa de } \\
\text { Lucros Futuros }\end{array}$ & $\begin{array}{l}\text { 1. Expectativa de Lucros Futuros } \\
\text { 2. Concessão/Exploração/Permissão }\end{array}$ \\
\hline Amortização & Até 40 anos & Até 20 anos & $\begin{array}{l}\text { 1. Até } 10 \text { anos } \\
\text { 2. Prazo Estabelecido }\end{array}$ \\
\hline \multicolumn{4}{|c|}{ Goodwill Negativo/Deságio } \\
\hline Definição & $\begin{array}{c}\text { Excesso do Valor Pago } \\
\text { sobre o Fair Value }\end{array}$ & $\begin{array}{c}\text { Excesso do Valor Pago } \\
\text { sobre o Fair Value }\end{array}$ & $\begin{array}{l}\text { Excesso do Valor Pago } \\
\text { sobre o Valor de Mercado }\end{array}$ \\
\hline Fundamento & $\begin{array}{c}\text { Expectativa de } \\
\text { Prejuízos Futuros }\end{array}$ & $\begin{array}{l}\text { Expectativa de } \\
\text { Prejuízos Futuros }\end{array}$ & $\begin{array}{l}\text { Expectativa de } \\
\text { Prejuízos Futuros }\end{array}$ \\
\hline Amortização & Até 40 anos & $\begin{array}{c}\text { Na medida em que incorrerem } \\
\text { os Prejuízos }\end{array}$ & Até 10 anos \\
\hline
\end{tabular}

Exemplos de Purchase Business Combinations

\begin{tabular}{|c|c|c|c|c|c|}
\hline \multicolumn{6}{|c|}{ Balanços Patrimoniais Antes da Aquisição (Em \$) } \\
\hline \multirow[t]{2}{*}{ Investidora } & & \multicolumn{4}{|c|}{ Investida } \\
\hline & & Valor & & $\begin{array}{c}\text { Valor de Mercado } \\
\text { (VM) }\end{array}$ & $\begin{array}{c}\text { Diferença } \\
\text { VM - VC }\end{array}$ \\
\hline \multirow[t]{3}{*}{ Caixa } & 1.000 & Caixa & 100 & & \\
\hline & & Estoques & 200 & 220 & +20 \\
\hline & & Terrenos & 150 & 180 & +30 \\
\hline \multirow[t]{2}{*}{ Total } & 1.000 & Total & 450 & & \\
\hline & & Financiamentos & 50 & 60 & +10 \\
\hline Capital & 1.000 & Capital & 400 & & \\
\hline Total & 1.000 & Total & 450 & & 40 \\
\hline
\end{tabular}

Neste exemplo, serão admitidas quatro hipóteses em que a empresa investidora adquire $100 \%$ dos ativos líquidos da investida e, em seguida, realizar-se-á uma análise comparativa de acordo com as normas e pronunciamentos previamente analisados. Por simpli- cidade será admitida a inexistência do reconhecimento de ativos intangíveis, contingências e passivos específicos decorrentes da operação.

Porém, a análise será efetuada com base nas demonstrações contábeis segundo as normas brasilei- 
ras. No balanço patrimonial da investidora, o custo de aquisição do controle de uma sociedade é apresentada na conta investimentos por meio do método de equivalência patrimonial (EP). Em seguida é apresentado o ágio ou o deságio, representado pela diferença para mais ou para menos, respectivamente, entre o custo de aquisição e a equivalência patrimonial.

Para a análise do tratamento o valor do patrimônio líquido contábil de $\$ 400$ da investida e do patrimônio líquido a valores de mercado no montante de $\$ 440$ serão mantidos constantes. A variação irá ocorrer em relação ao valor de compra de acordo com quatro hipóteses.
Hipótese I: Valor Pago $(\$ 440)=$ Valor de Mercado > Valor Contábil (\$400)

Segundo o APBO 16 e IAS 22, a diferença de $\$ 40$ entre o valor pago e o valor contábil é totalmente alocada aos respectivos ativos e passivos da investida. No Brasil essa diferença é reconhecida como ágio nas demonstrações contábeis individuais da controladora e é decorrente da diferença entre o valor de mercado dos ativos e passivos adquiridos e o valor contábil. Na consolidação o ágio é alocado aos respectivos ativos e passivos da investida. Portanto, os Balanços Consolidados são idênticos.

\begin{tabular}{|c|c|c|c|c|c|c|c|}
\hline \multicolumn{8}{|c|}{ Balanços Patrimoniais (Em \$) } \\
\hline \multicolumn{4}{|c|}{ BR-GAAP } & \multicolumn{4}{|c|}{ Consolidado } \\
\hline \multirow{2}{*}{\multicolumn{2}{|c|}{ Investidora }} & \multirow{2}{*}{\multicolumn{2}{|c|}{ Investida }} & \multicolumn{2}{|c|}{ Eliminações } & \multirow{2}{*}{$\begin{array}{c}\text { US-GAAP } \\
\text { e IASB }\end{array}$} & \multirow[t]{2}{*}{ BR-GAAP } \\
\hline & & & & Débito & Crédito & & \\
\hline \multirow[t]{3}{*}{ Caixa } & 560 & Caixa & 100 & & & 660 & 660 \\
\hline & & Estoques & 200 & 20 & & 220 & 220 \\
\hline & & Terrenos & 150 & 30 & & 180 & 180 \\
\hline Investimentos = E.P. & 400 & & & & 400 & - & - \\
\hline Ágio & 40 & & & & 40 & - & - \\
\hline \multirow[t]{2}{*}{ Total } & 1.000 & Total & 450 & & & 1.060 & 1.060 \\
\hline & & Financiamentos & 50 & & 10 & 60 & 60 \\
\hline Capital & 1.000 & Capital & 400 & 400 & & 1.000 & 1.000 \\
\hline Total & 1.000 & Total & 450 & & & 1.060 & 1.060 \\
\hline
\end{tabular}

Hipótese II: Valor Pago $(\$ 600)>$ Valor de Mercado (\$440) > Valor Contábil (\$400)

Conforme o APBO 16 e IAS 22, parte da diferença entre o valor pago e o valor contábil é alocada de acordo com o valor de mercado dos ativos e passivos adquiridos e o restante é reconhecido como goodwill.
No Brasil a diferença de $\$ 200$ entre o valor pago e o valor contábil é tratada como ágio, sendo que $\$ 40$ refere-se ao valor de mercado dos ativos e passivos e $\$ 160$ pode ser atribuído à expectativa de lucros futuros e/ou aquisição do direito de exploração, concessão ou permissão delegadas pelo Poder Público.

\begin{tabular}{|c|c|c|c|c|c|c|c|}
\hline \multicolumn{8}{|c|}{ Balanços Patrimoniais (Em \$) } \\
\hline \multicolumn{4}{|c|}{ BR-GAAP } & \multicolumn{4}{|c|}{ Consolidado } \\
\hline \multirow{2}{*}{\multicolumn{2}{|c|}{ Investidora }} & \multirow{2}{*}{\multicolumn{2}{|c|}{ Investida }} & \multicolumn{2}{|c|}{ Eliminações } & \multirow{2}{*}{$\begin{array}{c}\text { US-GAAP } \\
\text { IASB }\end{array}$} & \multirow[t]{2}{*}{ BR-GAAP } \\
\hline & & & & Débito & Crédito & & \\
\hline \multirow[t]{3}{*}{ Caixa } & 400 & Caixa & 100 & & & 500 & 500 \\
\hline & & Estoques & 200 & 20 & & 220 & 220 \\
\hline & & Terrenos & 150 & 30 & & 180 & 180 \\
\hline Investimentos & 400 & & & & 400 & - & - \\
\hline Ágio - Mercado & 40 & & & & 40 & - & - \\
\hline Ágio - Res. Futuro & 160 & & & & & Goodwill 160 & 160 \\
\hline \multirow[t]{2}{*}{ Total } & 1.000 & Total & 450 & & & 1.060 & 1.060 \\
\hline & & Financiamentos & 50 & & 10 & 60 & 60 \\
\hline Capital & 1.000 & Capital & 400 & 400 & & 1.000 & 1.000 \\
\hline Total & 1.000 & Total & 450 & & 40 & 1.060 & 1.060 \\
\hline
\end{tabular}


Hipótese III: Valor Pago $(\$ 400)=$ Valor Contábil $<$ Valor de mercado $(\$ 440)$

Nessa hipótese não há diferença entre o valor pago e o valor contábil, não existindo a figura do ágio/ deságio, de acordo com a legislação brasileira. En- tretanto, segundo o APBO 18, a diferença entre o valor pago e o valor de mercado deve ser alocada como redução dos ativos não circulantes, enquanto que o tratamento do IASB exige o reconhecimento dessa diferença como goodwill negativo, sendo reconhecido como receita diferida.

\begin{tabular}{|c|c|c|c|c|c|c|}
\hline \multicolumn{7}{|c|}{ Balanços Patrimoniais (Em \$) } \\
\hline \multicolumn{4}{|c|}{ BRASIL } & \multicolumn{3}{|c|}{ Consolidado } \\
\hline \multicolumn{2}{|c|}{ Investidora } & \multicolumn{2}{|c|}{ Investida } & \multirow{2}{*}{$\begin{array}{c}\text { US-GAAP } \\
700\end{array}$} & IASB & \multirow{2}{*}{$\begin{array}{c}\text { BR-GAAP } \\
700\end{array}$} \\
\hline Caixa & 600 & Caixa & 100 & & 700 & \\
\hline & & Estoques & 200 & 220 & 220 & 200 \\
\hline & & Terrenos & 150 & 140 & 180 & 150 \\
\hline Investimentos & 400 & & & - & - & - \\
\hline \multirow[t]{3}{*}{ Total } & 1.000 & Total & 450 & 1.060 & 1.100 & 1.050 \\
\hline & & & & & Receita Diferida 40 & \\
\hline & & Financiamentos & 50 & 60 & 60 & 50 \\
\hline Capital & 1.000 & Capital & 400 & 1.000 & 1.000 & 1.000 \\
\hline Total & 1.000 & Total & 450 & 1.060 & 1.100 & 1.050 \\
\hline
\end{tabular}

Por meio das demonstrações contábeis acima é possível se constatar uma das principais diferenças entre os pronunciamentos e normas. No balanço consolidado de acordo com o APBO 16, os estoques e passivos estão a valor de mercado, enquanto que os terrenos, único ativo não circulante, sofrem uma redução decorrente do acréscimo reconhecido nos demais itens. Segundo as normas do IASB, os ativos e passivos são reconhecidos pelo valor de mercado e o goodwill negativo é reconhecido como receita. No Brasil, o balanço consolidado mantém os valores contábeis.

\section{Hipótese IV:Valor Pago (\$200) < Valor Contábil (\$400) < Valor de Mercado (\$440)}

De acordo com o APBO 16, o valor da diferença entre o valor pago e o valor contábil deve reduzir os ativos não circulantes até atingir a zero, sendo o res- tante reconhecido como crédito diferido. Segundo o IASB, a diferença entre o valor pago e o valor de mercado é denominada de goodwill negativo, sendo reconhecido como: a) receita na medida em que incorrerem os prejuízos estimados, caso tenha fundamento econômico com base em expectativa de prejuízos futuros; b) receita com base na vida útil média remanescente dos ativos depreciáveis/amortizáveis, caso não tenha fundamento econômico e a quantia do goodwill negativo não exceder o valor de mercado dos ativos não monetários; e c) receita imediata, caso não tenha fundamento econômico e a quantia do goodwill negativo exceder o valor de mercado dos ativos não monetários. No Brasil, os ativos e passivos adquiridos são mantidos aos respectivos valores contábeis e o deságio é classificado no sub-grupo resultados de exercícios futuros (REF).

\begin{tabular}{|c|c|c|c|c|c|c|}
\hline \multicolumn{7}{|c|}{ Demonstrações Contábeis (Em \$) } \\
\hline \multicolumn{4}{|c|}{ BRASIL } & \multicolumn{3}{|c|}{ Consolidado } \\
\hline \multicolumn{2}{|c|}{ Investidora } & \multicolumn{2}{|l|}{ Investida } & \multirow{2}{*}{$\begin{array}{r}\text { US-GAAP } \\
900\end{array}$} & IASB & \multirow{2}{*}{$\begin{array}{c}\text { BR-GAAP } \\
900\end{array}$} \\
\hline Caixa & 800 & Caixa & 100 & & 900 & \\
\hline & & Estoques & 200 & 220 & 220 & 200 \\
\hline & & Terrenos & 150 & 0 & 180 & 150 \\
\hline Investimentos & 400 & & & - & - & - \\
\hline Deságio & $(200)$ & & & - & & - \\
\hline \multirow[t]{3}{*}{ Total } & 1.000 & Total & 450 & 1.120 & 1.300 & 1.250 \\
\hline & & Financiamentos & 50 & 60 & 60 & 50 \\
\hline & & & & Crédito Diferido 60 & Receita Diferida & REF 200 \\
\hline Capital & 1.000 & Capital & 400 & 1.000 & 1.000 & 1.000 \\
\hline Total & 1.000 & Total & 450 & 1.120 & 1.300 & 1.250 \\
\hline
\end{tabular}


Nessa hipótese é possível se constatar significativas diferenças entre os pronunciamentos e normas. $O$ APBO 16 não atribuía valor aos terrenos, enquanto que no IASB os ativos e passivos adquiridos são reconhecidos pelo valor de mercado e o goodwill negativo é reconhecido como receita diferida. No Brasil, os ativos e passivos adquiridos permanecem com os valores contábeis.

Outra diferença significativa refere-se à amortização do goodwill/goodwill negativo, quando fundamentado em expectativa de lucros/prejuízos futuros. O APBO 16 fixava um período máximo de 40 anos. O IASB determina até 20 anos, sendo passível de ampliação com as devidas justificativas. No Brasil, a CVM fixa em 10 anos o prazo máximo para tal amortização.

Diante dessa diversidade, a amortização dos valores diferidos geram despesa/receita e podem causar expressiva diferença na posição patrimonial e no resultado de uma empresa, tornando-se um fator de dificultação para a harmonização contábil.

\section{PUSH-DOWN ACCOUNTING}

O método push-down accounting exige que se realizem e evidenciem os ajustes dos ativos e passivos das sociedades investidas ao valor de mercado. Entretanto, a SEC exige apenas em determinadas circunstâncias a aplicação deste método, principalmente quando, em uma business combinations, o valor pago por esses itens patrimoniais for diferente do valor contábil.

De acordo com FIPECAFI \& Arthur Andersen ${ }^{13}$. "Os novos valores são atribuídos aos ativos e passivos da investida pela distribuição do ágio (ou deságio) nas correspondentes contas, até o limite dos valores de mercado. O eventual valor excedente pago pela investidora é registrado como goodwill, representando esse o verdadeiro goodwill da investida." (Grifo nosso)

O método push-down accounting gera efeito nas demonstrações contábeis da sociedade investida. $\mathrm{O}$ balanço patrimonial evidencia os ativos e passivos ao valor de mercado e o respectivo ajuste de avaliação, também chamado "ajuste de push-down". Na apuração do resultado da investida, os efeitos sobre os itens patrimoniais serão reconhecidos no momento da realização, pois serão baixados ou depreciados com base no valor de mercado. O impacto no resultado da empresa irá gerar efeito no cálculo da equivalência patrimonial.

A SEC não obriga a aplicação do push-down accounting nos casos em que a investida emite ações preferenciais dispersas com muitos acionistas minoritários, mas exige caso a caso em situações específicas.

Segundo Delaney ${ }^{14}$, a aplicação generalizada dessa nova base contábil foi discutida, nos Estados Unidos, por meio de um memorando em 1991, não se obtendo consenso. De acordo com esse autor, o FASB retirou, em 1996, essa questão da agenda de debates.

Epstein ${ }^{15}$ aborda o tratamento internacional do push-down accounting e analisa a polêmica sobre sua constituição. Não é apresentada qualquer determinação do IASB sobre sua obrigatoriedade.

\section{Exemplo de Push-Down Accounting}

\begin{tabular}{|c|c|c|c|c|c|}
\hline \multicolumn{6}{|c|}{ Balanços Patrimoniais Antes da Aquisição (Em \$) } \\
\hline \multicolumn{2}{|c|}{ Investidora } & \multicolumn{4}{|c|}{ Investida } \\
\hline & & Valor & & $\begin{array}{c}\text { Valor de Mercado } \\
\text { (VM) }\end{array}$ & $\begin{array}{c}\text { Diferença } \\
\text { VM - VC }\end{array}$ \\
\hline \multirow[t]{3}{*}{ Caixa } & 1.000 & Caixa & 100 & & \\
\hline & & Estoques & 200 & 220 & +20 \\
\hline & & Terrenos & 150 & 180 & +30 \\
\hline \multirow[t]{2}{*}{ Total } & 1.000 & Total & 450 & & \\
\hline & & Financiamentos & 50 & 60 & +10 \\
\hline Capital & 1.000 & Capital & 400 & & \\
\hline Total & 1.000 & Total & 450 & & 40 \\
\hline
\end{tabular}

\footnotetext{
${ }^{13}$ FIPECAFI \& Arthur Andersen. Normas e Práticas Contábeis no Brasil. 2 2a ed. São Paulo: Atlas, 1994, p. 656.

14 Op. cit., p. 387.

${ }^{15}$ EPSTEIN, Barry J. \& MIRZA, Abbas Ali. IAS 97: Interpretation and Application of Internacional Accounting Standards 1997. USA: Wiley, 1997, p. 362.
} 
Admitindo os mesmos dados iniciais e a hipótese I do exemplo anterior - em que a investidora adquiriu $100 \%$ das ações com direito a voto da investida por $\$ 440$; temos as seguintes demonstrações sem e com a aplicação do push-down accounting:

\begin{tabular}{|c|c|c|c|c|c|}
\hline \multicolumn{6}{|c|}{ Balanços Patrimoniais Após a Aquisição (Em \$) - Sem Push-Down Accounting } \\
\hline Caixa & 560 & Caixa & 100 & $\begin{array}{c}\text { Alocação da } \\
\text { diferença }\end{array}$ & $\begin{array}{c}\text { Consolidado } \\
660\end{array}$ \\
\hline & & Estoques & 200 & +20 & 220 \\
\hline & & Terrenos & 150 & +30 & 180 \\
\hline Investimentos & 440 & & & & - \\
\hline Total & 1.000 & Total & 450 & & 1.060 \\
\hline & & Financiamentos & 50 & +10 & 60 \\
\hline Capital & 1.000 & Capital & 400 & & 1.000 \\
\hline Total & 1.000 & Total & 450 & 40 & 1.060 \\
\hline
\end{tabular}

Todavia, o push-down exige a evidenciação e divulgação das demonstrações contábeis da sociedade investida de acordo com os respectivos valores de mercado, sendo necessário o seguinte lançamento de ajuste:

\begin{tabular}{|lc|}
\hline Lançamento de Ajuste- Push-Down Accounting (na Investida) \\
\hline D - Estoques & 20 \\
\hline D - Terrenos & 30 \\
\hline C - Financiamentos & 10 \\
\hline C - Ajuste de Push-Down & 40 \\
\hline
\end{tabular}

\begin{tabular}{|c|c|c|c|c|c|c|}
\hline \multicolumn{7}{|c|}{ Balanços Patrimoniais (Em \$) - Com Push-Down Accounting } \\
\hline \multicolumn{2}{|c|}{ Investidora } & \multicolumn{2}{|c|}{ Investida } & \multicolumn{2}{|c|}{ Eliminações } & \multirow{3}{*}{$\begin{array}{c}\text { Consolidado } \\
660\end{array}$} \\
\hline & & & & \multicolumn{2}{|c|}{ Débito Crédito } & \\
\hline Caixa & 560 & Caixa & 100 & & & \\
\hline & & Estoques & 220 & & & 220 \\
\hline & & Terrenos & 180 & & & 180 \\
\hline Investimentos & 440 & & & & 440 & \\
\hline Total & 1.000 & Total & 500 & & & 1.060 \\
\hline & & Financiamentos & 60 & & & 60 \\
\hline Capital & 1.000 & Capital & 400 & 400 & & 1.000 \\
\hline & & Ajuste de Push-Down & 40 & 40 & & \\
\hline Total & 1.000 & Total & 500 & & & 1.060 \\
\hline
\end{tabular}

Dessa forma, o balanço patrimonial da investida está avaliado ao valor de mercado - que é justamente o valor pago pelo comprador, e reconhece o ajuste de avaliação. A demonstração abaixo destaca as diferenças relativas ao balanço patrimonial com a aplicação ou não do método push-down accounting.

\begin{tabular}{|l|c|c|}
\hline \multicolumn{3}{|c|}{ Balanços Patrimoniais da Investida (Em \$) } \\
\hline & Sem Push-Down & Com Push-Down \\
\hline Caixa & 100 & 100 \\
\hline Estoques & 200 & 220 \\
\hline Terrenos & 150 & 180 \\
\hline Total & $\mathbf{4 5 0}$ & $\mathbf{5 0 0}$ \\
\hline Financiamentos & 50 & 60 \\
\hline Capital & 400 & 400 \\
\hline Ajuste de Push-Down & - & 40 \\
\hline Total & $\mathbf{4 5 0}$ & $\mathbf{5 0 0}$ \\
\hline
\end{tabular}


É importante notar que a conta "ajuste de pushdown" no patrimônio líquido da investida (em seu balanço patrimonial individual) corresponde a uma reserva de reavaliação; só que decorrente de uma transação efetivada entre efetivos terceiros.

\section{ALGUMAS CONSIDERAÇÕES FISCAIS}

Os aspectos tributários são considerados relevantes no planejamento de uma reorganização societária - seja nas operações de fusão, incorporação ou aquisição.

Nas operações de business combinations reconhecidas pelo pooling, existe a troca de ações com direito a voto e os valores contábeis das sociedades combinadas são mantidos. Portanto, essas transações não estão sujeitas à tributação nas pessoas jurídicas cujas ações foram trocadas.

Conseqüentemente, as empresas que planejam uma reorganização societária tendem a preferir a manutenção dos valores contábeis com o propósito de não estarem sujeitas a tributação nesse momento.

Contudo, nas fusões e incorporações em que o ágio ou deságio cujo fundamento seja a diferença entre o valor de mercado de bens ou direitos do ativo e o custo registrado na contabilidade (valor contábil), este ágio ou deságio integrará o custo do respectivo bem ou direito, para efeito de apuração de ganho ou perda de capital da sociedade vendedora.

É importante considerar que a legislação fiscal brasileira penaliza algumas empresas que reconhecem o ágio cujo fundamento seja fundo de comércio, ativos intangíveis e outras razões econômicas devido ao fato de não ser permitida a sua amortização. Nestes casos, o ágio ou deságio deve ser:16

a) computado na determinação do custo de aquisição, na apuração de ganho ou perda de capital, no caso de alienação do direito que lhe deu causa ou de sua transferência para sócio ou acionista, na hipótese de devolução do capital;

b) deduzido como perda, se ágio, no encerramento das atividades da empresa, se comprovada, nessa data, a existência do fundo de comércio ou do ativo intangível que lhe deu causa; e c) computado como receita, se deságio, no encerramento das atividades da empresa.

Dessa forma, esses ágios ou deságios não são dedutíveis (tributáveis), pois não é permitida amortização. Os efeitos fiscais são reconhecidos apenas quando da baixa do investimento a que se vinculam.

Entretanto, o ágio ou deságio decorrente de expectativa de resultados futuros deve ser amortizado nos balanços correspondentes à apuração do lucro real levantados posteriormente à incorporação ou fusão, à razão de 1/60 (um sessenta avos) - no máximo, em caso de ágio; e no mínimo, em caso de deságio para cada mês do período de apuração.

Conseqüentemente, o ágio é dedutível (amortizado) quando ocorrem as operações de fusão ou incorporação, o que incentiva essas reorganizações societárias. Logo, temos incentivo fiscal à fusão e incorporação e desincentivo ao uso dos valores de mercado nessas operações.

\section{FASB e Novo Tratamento Contábil ${ }^{17}$}

Em setembro de 1999, o FASB emitiu uma Minuta (Exposure Draft) de proposta de pronunciamento (statement) para contabilização de business combinations e ativos intangíveis.

Este Exposure Draft alteraria o APBO 16 - Business Combinations - ao proibir o método pooling of interests para o reconhecimento das operações de business combinations após a divulgação da data final de emissão do statement.

Também seria alterado o APBO 17- Intangible Assets - ao reduzir o período máximo de amortização do goodwill de 40 anos para 20 anos e ao presumir que os demais ativos intangíveis adquiridos possuem uma vida econômica de até 20 anos.

No entanto, durante abril de 2000 até janeiro de 2001, o FASB redefiniu as alterações propostas em 1999 e realizou significativas mudanças. Como resultado, foi emitido em fevereiro de 2001 um novo documento - Exposure Draft, revisado e submetido à Audiência Pública ${ }^{18}$, o qual propõe um novo tratamento contábil para o goodwill adquirido e para os ativos in-

\footnotetext{
${ }^{16}$ Instrução Normativa SRF n ${ }^{\circ} 011$, de 10 de fevereiro de 1999 , artigo $1^{\circ}$, parágrafo $3^{\circ}$, inciso III.

${ }^{17}$ Adaptado de FASB - Financial Accounting Standards Board. Exposure Draft (Revised): Proposed Statement of Financial Accounting Standards "Business Combinations and Intangible Assets-Accounting for Goodwill'. USA: Financial Accounting Series, 14 de fevereiro de 2001.

${ }^{18}$ Encerrada em 16 de março de 2001.
} 
tangíveis. Os principais aspectos contidos nesta nova proposta são:

$\Rightarrow$ o goodwill não seria mais amortizado anualmente, mas teria que ser testado periodicamente através do método do impairment (perda de valor) de forma diferente de outros ativos sujeitos ao impairment. O impairment seria reconhecido caso o valor de mercado ${ }^{19}$ do goodwill de uma unidade de negócio ${ }^{20}$ fosse menor que o seu valor contábil registrado na data de aquisição.

$\Rightarrow$ a contabilização dos ativos intangíveis adquiridos, com exceção do goodwill, seria alterada;

$\Rightarrow$ o método pooling of interests seria proibido para o reconhecimento de business combinations após a divulgação da data final de emissão do statement; $\mathrm{e}$

$\Rightarrow$ as exigências contidas no Interpretation № 4 Applicability of FASB Statement $N$ № 2 to Business Combination Accounted for by the Purchase Method, seriam mantidas.

Contudo, estas propostas foram apreciadas e o FASB aprovou em 29 de junho de 2001 e divulgou em 30 de junho de 2001 dois pronunciamentos: SFAS 141 - Business Combinations e SFAS 142 - Goodwill and Other Intangible Assets. As principais mudanças no tratamento contábil para as operações de business combinations são:

$\Rightarrow$ eliminação do pooling e aplicação do purchase para todas as operações de fusões, incorporações e aquisições a partir de julho de 2001;

$\Rightarrow$ não amortização do goodwill a partir de 2002 para todas as operações de fusões, incorporações e aquisições, realizadas antes de julho de 2001;

$\Rightarrow$ não amortização do goodwill para todas as operações de fusões, incorporações e aquisições, realizadas a partir de julho de 2001 ;

$\Rightarrow$ a partir de 2002, reconhecer o impairment do goodwill adquirido em todas as operações de fusões, incorporações e aquisições por meio da aplicação do teste com base no valor de mercado (fair-value-based test), a ser realizado pelo menos uma vez por ano. Esse teste pode se basear no fluxo de caixa não descontado. De forma genérica, a investidora deve realizar o teste para a(s) unidade(s) de negócios do segmento(s) operacional(is), que representa(m) a investida. O impairment deve ser reconhecido caso o valor de mercado do goodwill da unidade de negócio seja menor que o seu valor contábil registrado na data de aquisição.

As determinações que permanecem inalteradas em relação ao APBO 16 são:

$\Rightarrow$ o método da compra exige que os ativos líquidos de uma empresa adquirida sejam reconhecidos pelo valor de mercado;

$\Rightarrow$ contabilizar como despesa o custo efetivo incorrido em pesquisa e desenvolvimento na data da aquisição, conforme estabelecido em Interpretation № 4.

O SFAS 142 alterou o APBO 17 ao não permitir a amortização do goodwill e reconhecer o valor de mercado de outros ativos intangíveis por meio de contrato ou outro instrumento jurídico, ou da possibilidade de venda, transferência, licença, aluguel e negociação, independentemente da intenção da investidora em realizar essas operações.

\section{CONSOLIDAÇÃO}

As demonstrações contábeis consolidadas fornecem informações do conjunto de empresas como se fossem uma única entidade econômica, e constitui uma extensão do postulado da entidade, indicando a predominância do conceito da entidade econômica sobre a jurídica. Considera-se que a dimensão econômica da entidade é mais importante, em termos informacionais, do que a caracterização legal das empresas constituídas.

O balanço patrimonial consolidado evidencia os saldos dos ativos e passivos com terceiros, e sua demonstração de resultado indica as receitas e despesas com terceiros, sendo que a participação minoritária deve ser apresentada de forma destacada, idealmente, imediatamente antes do patrimônio líquido.

Em relação ao processo de consolidação, quando

\footnotetext{
${ }^{19}$ São relacionadas várias determinações para se obter o valor de mercado implícito do goodwill em relação à unidade reportada.

${ }^{20}$ Unidade de negócio é definida como o menor nível de uma entidade que representa um negócio e que pode ser distinguido, fisicamente e operacionalmente e para fins de geração de relatórios internos, de outras atividades, operações e ativos desta entidade.
} 
a participação é inferior a 100\%, a literatura acadêmica aborda os métodos pleno e proporcional. O método pleno reconhece a totalidade dos ativos, passivos e contas de resultado com a segregação da participação minoritária (acionistas não controladores). O método proporcional é utilizado na contabilização de joint ventures, reconhecendo apenas a porcentagem de cada investidor (venturer) nos investimentos controlados em conjunto.

A exigência da elaboração da consolidação proporcional das demonstrações contábeis refere-se às sociedades controladas em conjunto (joint ventures) e possui aspectos divergentes. Os US-GAAP determinam, de forma geral, que essas empresas não sejam consolidadas, sendo reconhecidas de acordo com a equivalência patrimonial na conta investimentos. São previstas exceções, como nos casos das empresas de petróleo.

No Brasil, exige-se a consolidação proporcional para as sociedades controladas em conjunto.

O IASB apresenta duas opções. Como tratamento preferencial deve ser efetuada a consolidação proporcional como no Brasil; e como tratamento alternativo pode-se seguir o procedimento contábil efetuado nos Estados Unidos de reconhecer os investimentos em joint ventures de acordo com o método da equivalência patrimonial.

Conforme Parker \& Nobes ${ }^{21}$, as demonstrações consolidadas foram inicialmente divulgadas nos Estados Unidos, sendo que algumas companhias publicaram-nas no século passado. Entretanto, a United States Steel Company, licenciada em Nova Jersey em 1901, foi a primeira empresa americana a desenvolver um modelo e publicar as demonstrações consolidadas desde o seu início. De acordo com esses autores:

"Na Inglaterra e Europa continental, as empresas controladoras e as demonstrações consolidadas tiveram um desenvolvimento posterior. As demonstrações consolidadas são primeiramente mencionadas na legislação da Inglaterra em 1947, da Alemanha Ocidental em 1965, e da França em 1985."
A introdução da consolidação no Brasil deu-se pela Lei no 6.404/76. Atualmente, a CVM exige a consolidação das demonstrações contábeis da controladora aberta e de suas controladas, introduzindo a consolidação proporcional para as sociedades sob controle compartilhado; e da sociedade comando de grupo de sociedades que inclua companhia aberta.

De acordo com a legislação brasileira e internacional, pode-se dizer que existe um avanço do Brasil em relação aos outros países. Martins ${ }^{22}$ relata que:

"Nos países em que se processa há tantos anos a consolidação dos balanços, desenvolveu-se inicialmente, a regra básica de que só se consolidam demonstrações de controladora e controlada(s), ou de empresas sob controle comum. Mas sempre permanecendo o conceito de que só pode haver consolidação plena de balanços e de resultados quando há efetivamente a figura do controle. Depois, evoluiu-se para a figura do controle compartilhado (joint ventures) "

Com base na literatura contábil, constata-se que a consolidação surgiu inicialmente onde o foco é o controle; posteriormente, evoluiu para o controle compartilhado, por meio da consolidação proporcional, e, por último, para o método de equivalência patrimonial, para refletir em uma única linha (one line consolidation) a participação da investidora nos resultados em investimentos com influência significativa sobre a investida. Considerando esses aspectos, Martins ${ }^{23}$ afirma que:

"É interessante, então, saber-se que, historicamente, primeiro nasceu a consolidação de balanços, e só depois, como forma de complementar as demonstrações consolidadas, surgiu a equivalência para os investimentos em não controladas, mas só sobre as quais houvesse a figura da influência ou possibilidade de influência (afinal, as controladas não precisavam de equivalência, já que estavam consolidadas).

\footnotetext{
${ }^{21}$ PARKER, Robert \& NOBES, Christopher. International Accounting. EUA: Wiley, 1998, p. 325-326.

${ }^{22}$ MARTINS, Eliseu Quais Investimentos Devem Ser Avaliados pela Equivalência Patrimonial? - Há Novidades (I). São Paulo: IOB - Informações Objetivas, Boletim Temática Contábil e Balanços, $\mathrm{n}^{\circ} 34,3^{\mathrm{a}}$ semana de agosto de 1997. p. 1.

${ }^{23}$ Id. Ibid.
} 
Por isso, é comum nessa forma de avaliação (equity method) a utilização, na língua inglesa, da expressão "one line consolidation". Ou seja, a equivalência patrimonial é uma forma simplificada de consolidação numa linha só, já que, ajustando-se uma única linha do balanço, a dos investimentos, produz-se a incorporação da parcela do lucro ou do prejuízo da investida que cabe à investidora."

\section{QUANDO OU NÃO CONSOLIDAR}

As demonstrações consolidadas devem incluir todas as subsidiárias em que a investidora detém, direta ou indiretamente, a maioria do capital votante, representada pela participação acionária acima de 50\% das ações com direito a voto, e abrangem tanto as controladas localizadas no país quanto as localizadas no exterior.
No Brasil, exige-se a divulgação das demonstrações contábeis consolidadas para companhia aberta que possuir investimentos em sociedades controladas, incluindo as sociedades controladas em conjunto, e sociedade de comando de grupo de sociedades que inclua companhia aberta.

Torna-se importante ressaltar que o fato de a investidora possuir controladas atuando em setores diversificados não constitui motivo para sua exclusão da consolidação. Outro aspecto significativo, e também em linha com as práticas internacionais, é que não devem ser excluídas da consolidação as sociedades controladas cujas operações sejam de natureza diferente das operações da controladora ou das demais controladas.

O quadro seguinte apresenta as condições, geralmente exigidas, para a consolidação ou não das demonstrações contábeis.

\begin{tabular}{|c|c|c|c|}
\hline \multicolumn{4}{|c|}{ Quadro X - Quando ou Não Consolidar } \\
\hline Consolidação & US-GAAP & IASB & BR-GAAP \\
\hline Controle Direto & $\checkmark$ Previsto & $\checkmark$ Previsto & $\checkmark$ Previsto \\
\hline Controle Indireto & $\checkmark$ Previsto & $\checkmark$ Previsto & $\checkmark$ Previsto \\
\hline \multicolumn{4}{|l|}{ Exceções } \\
\hline Controle Temporário & $\checkmark$ Previsto & $\checkmark$ Previsto & $\checkmark$ Previsto \\
\hline Restrições de Longo Prazo & $\checkmark$ Previsto & $\checkmark$ Previsto & $\checkmark$ Previsto \\
\hline Subsidiária Virtualmente Integral & $\checkmark$ Previsto (SEC) & $\checkmark$ Previsto & $\checkmark$ Previsto (CVM) \\
\hline Subsidiária Integral & $\checkmark$ Previsto (SEC) & $\checkmark$ Previsto & $\checkmark$ Previsto (CVM) \\
\hline
\end{tabular}

Conforme o quadro acima, pode-se afirmar que os US-GAAP, IASB e BR-GAAP possuem uma particularidade quanto à exigência da consolidação. Uma empresa controladora é dispensada/facultada de apresentar demonstrações consolidadas se essa for integral, ou virtualmente integral, e for controlada por outra sociedade.

Conforme o Quadro V, apresentado no item 5.2 Investimentos em Participações Societárias no Capital Votante, considera-se holding virtualmente integral quando a controladora possuir $90 \%$ ou mais de participação societária no capital votante e inferior a 100\%. Nesse caso, o IASB determina que a não divulgação das demonstrações consolidadas deve ser aprovada pelos acionistas minoritários.

As subsidiárias integral e virtualmente integral, que não divulgam as demonstrações consolidadas, devem evidenciar em suas demonstrações contábeis indivi- duais a sociedade controladora que divulga as demonstrações consolidadas.

Dessa maneira, considera-se que as demonstrações consolidadas da sociedade controladora de cima são mais importantes aos usuários da informação contábil.

\section{EVIDENCIAÇÃO}

O ARB 51, parágrafo 5, somente menciona que a consolidação deve ser evidenciada no próprio corpo das demonstrações contábeis ou em notas explicativas, cada empresa responsabilizando-se por sua extensão. Entretanto, evidenciações específicas deverão ocorrer nas hipóteses da existência de controladas não consolidadas e investidas com data de encerramento do exercício social diferente da controladora. 
De acordo com o IASB, a controladora que divulga demonstrações contábeis consolidadas deve evidenciar os seguintes esclarecimentos:

$\checkmark$ relação de subsidiárias, incluindo nome, país, sede, proporção da participação acionária e, se for diferente, a proporção de poder de voto;

$\checkmark$ descrição do método utilizado para contabilizar os investimentos em subsidiárias;

$\checkmark$ as razões para não consolidar uma subsidiária;

$\checkmark$ a natureza do relacionamento entre a controladora e uma subsidiária na qual a controladora não possui, direta ou indiretamente, mais da metade do poder de voto;

$\checkmark$ nome da empresa que possui, direta ou indiretamente, mais da metade do poder de voto mas que não é consolidada devido à ausência de controle; e

$\checkmark$ efeito decorrente de aquisições ou vendas de subsidiárias sobre a posição financeira na data das demonstrações contábeis, o resultado do período, assim como os saldos correspondentes aos do período anterior.

O artigo 31 da Instrução CVM no 247 referente à consolidação determina que as notas explicativas contenham informações precisas, indicando:

$\checkmark$ critérios adotados na consolidação e as razões pelas quais foi excluída determinada controlada;

$\checkmark$ eventos subseqüentes à data de encerramento do exercício social que tenham, ou possam vir a ter, efeito relevante sobre a situação financeira e os resultados futuros consolidados;

$\checkmark$ efeitos, nos elementos do patrimônio e resultado consolidados, da aquisição ou venda de sociedade controlada, no transcorrer do exercício social, assim como da inserção de controlada no processo de consolidação, para fins de comparabilidade das demonstrações contábeis; e

$\checkmark$ eventos que ocasionaram diferença entre os montantes do patrimônio líquido e do lucro ou prejuízo líquido da investidora, em confronto com os correspondentes montantes do patrimônio líquido e lucro líquido ou prejuízo consolidados.

CONCLUSÃO

As operações de business combinations foram destacadas de acordo com o cenário atual e aborda- das conforme os principais pronunciamentos e normas contábeis dos US-GAAP, IASB e Brasil.

Apresentaram-se as características dos investimentos permanentes em controladas, os principais termos, o tratamento contábil, os métodos de avaliação, a necessidade ou não de consolidação e as evidenciações exigidas.

A principal constatação deste estudo é a de que foi observada a existência de várias restrições para a harmonização das práticas contábeis.

Dentre elas, uma refere-se especificamente à classificação dos investimentos em participações societárias. Os US-GAAP e o IASB utilizam como parâmetro a participação em ações ordinárias com direito a voto, enquanto que, no Brasil, os parâmetros utilizados na determinação dos investimentos societários concentram-se no capital social, que inclui ações preferenciais. Entretanto, foram utilizadas neste estudo as denominações "ações com direito a voto" ou "ações votantes" ou "ações ou quotas com direito a voto", devido ao fato de que as ações preferenciais, no Brasil, podem conceder esse direito.

Uma variável importante nessa classificação é o percentual de participação na investida, sendo que os US-GAAP exigem mais de $50 \%$ do capital votante para as controladas, enquanto que o IASB e a legislação brasileira determinam o controle direto ou indireto com base, entre outros, na preponderância nas deliberações sociais e o poder de eleger ou destituir a maioria dos administradores.

Porém, os US-GAAP e o IASB utilizam $20 \%$ do capital votante para as coligadas, enquanto que, no Brasil, o parâmetro é de $10 \%$ do capital social.

A restrição mais acentuada refere-se às operações de business combinations. O FASB e IASB têm emitido pronunciamentos ou normas específicos com métodos de avaliação que enfocam a forma de combinação de empresas e procedimentos a serem realizados antes, durante e após a data efetiva da combinação. No Brasil, existe uma legislação restrita para o tema.

Observou-se, também, que os US-GAAP e o IASB procuram refletir a essência econômica das operações de business combinations, enquanto que, no Brasil, o reconhecimento contábil segue a forma jurídica e, principalmente, o impacto fiscal da transação.

Contudo, outra significativa restrição diz respeito, diretamente, ao cálculo do goodwill. A diversidade de 
tratamentos foi apresentada de acordo com o FASB, o IASB e a CVM.

Outra diferença relevante refere-se ao período máximo para a amortização do goodwill. Os US-GAAP adotavam o período máximo de 40 anos, enquanto que o IASB fixa em 20, e a CVM, em 10 anos.

O FASB divulgou dois pronunciamentos com significativas mudanças do tratamento contábil do goodwill, inclusive do goodwill negativo. Deve-se reconhecer a perda do valor do goodwill adquirido por meio do teste de impairment.

Ressalta-se também que a amortização do goodwill negativo e do deságio com fundamento econômico, estabelecidos pelo IASB e CVM, geram receita para a investidora e os prazos também são diferentes. Os US-GAAP estabeleciam o prazo máximo de 40 anos; enquanto que o Brasil fixa em até 10 anos e o IASB estabelece o reconhecimento como receita à medida em que incorrerem os prejuízos previstos.

Nesse contexto, a CVM exige mais rigor com a amortização do deságio não justificado pelos fundamentos econômicos, permitindo sua amortização somente nos casos de venda ou perecimento do inves- timento; dessa forma, é possível evitar o reconhecimento de receitas de forma inadequada, o que é aceito pela norma atual do IASB.

Para fins de harmonização, é relevante fixar um período adequado de amortização, que reflita a realidade empresarial e que seja praticado em diversos países.

Todavia, constatou-se também que as normas e pronunciamentos contábeis analisados exigem a evidenciação (de forma clara) das práticas contábeis adotadas e, principalmente, da consolidação das demonstrações contábeis para as sociedades que obtêm controle sobre a empresa investida.

Finalmente, foi possível identificar as principais variáveis que afetam a uniformidade das práticas contábeis atuais para as operações de business combinations, e a consolidação das demonstrações contábeis, assim como identificar aspectos relevantes para a adoção do tratamento contábil adequado nessas operações.

Conclui-se, então, pela necessidade de um trabaIho ainda grande para se conseguir a harmonização mundial desse tema tratado.

\section{REFERÊNCIAS BIBLIOGRÁFICAS}

BRASIL. Lei nำ 6.404, de 15 de dezembro de 1976 . Dispõe sobre as Sociedades por Ações.

. Lei no 9.457, de 05 de maio de 1997. Altera dispositivos da Lei no 6.404 .

Decreto no 3.000 , de 26 de março de 1999. Dispõe sobre o Regulamento do Imposto de Renda.

Instrução Normativa SRF ㄲo 011 , de 10 de fevereiro de 1999. Dispõe sobre o registro e amortização de ágio ou deságio nas hipóteses de incorporação, fusão e cisão.

. Instrução CVM no 247, de 27 de março de 1996.

Instrução CVM no 285, de 31 de julho de 1998.

Instrução CVM no 319 , de 3 de dezembro de 1999.

Instrução CVM no 320 , de 4 de dezembro de 1999.
DELANEY, Patrick R. et alii. GAAP 97: Interpretation and Application of Generally Accepted Accounting Principles 1997. USA: Wiley, 1997.

EL HAJJ, Zaina Said. "Business Combination" e Consolidação das Demonstrações Contábeis uma abordagem comparativa entre as normas dos USGAAP, IASB e Brasil. São Paulo, 1999. Dissertação de Mestrado, FEA/USP.

EPSTEIN, Barry J. \& MIRZA, Abbas Ali. IAS 97: Interpretation and Application of Internacional Accounting Standards 1997. USA: Wiley, 1997.

FASB - Financial Accounting Standards Board. Original Pronouncements 1997/98 Edition. Accounting Standards as of June 1, 1997. USA:Wiley, 1998.

Exposure Draft (Revised): Proposed Statement of Financial Accounting Standards "Business Combinations and Intangible Assets-Accounting for Goodwill". USA: Financial Accounting Series, 14 de fevereiro de 2001. 
FIPECAFI - Fundação Instituto de Pesquisas Contábeis, Atuariais e Financeiras. Manual de Contabilidade das Sociedades por Ações: aplicável também as demais sociedades. $5^{\underline{a}}$ ed. São Paulo: Atlas, 2000.

FIPECAFI \& Arthur Andersen. Normas e Práticas Contábeis no Brasil. 2ª ed. São Paulo: Atlas, 1994.

IASB - International Accounting Standards Committee. IAS 22 - Business Combinations. Emitido em 1983 e revisado em 1998.

\section{IAS 27 - Consolidated Financial}

Statements and Accounting for Investments in Subsidiaries. Emitido em 1988 e revisado em 1994.

KPMG Corporate Finance. Fusões \& Aquisições. Relatório disponível em: http://www.kpmg.com.br. Acesso em fevereiro de 2000.

KIESO, Donald E. \& WEYGANDT, Jerry J. Intermediate Accounting. 9aㅡ ed. New York: Wiley, 1998.

MARTINS, Eliseu. Contribuição à Avaliação do Ativo Intangível. São Paulo, 1972. Tese de Doutorado, FEA/USP.

Goodwill (Fundo de Comércio) - Um Campo Fértil para o Avanço da Contabilidade.
São Paulo: IOB - Informações Objetivas, Bole-

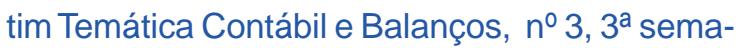
na de janeiro de 1996.

. Quais Investimentos Devem Ser Avaliados pela Equivalência Patrimonial? - Há Novidades (I). São Paulo: IOB - Informações Objetivas, Boletim Temática Contábil e Balanços, no 34, 3로ำ semana de agosto de 1997.

Participações Societárias - Método da Equivalência Patrimonial - Consolidação de Demonstrações Contábeis - Perguntas e Respostas (1ª parte). São Paulo: IOB - Informações Objetivas, Boletim Temática Contábil e Balanços, no 43, 4ª semana de outubro de 1997.

Participações Societárias - Método da Equivalência Patrimonial - Consolidação de Demonstrações Contábeis - Perguntas e Respostas ( $2^{\mathrm{a}}$ e última parte). São Paulo: IOB - Informações Objetivas, Boletim Temática Contábil e Balanços, ํㅜ 44, 5ª semana de outubro de 1997.

NEUMANN, Denise. Compra de empresas atrai o investimento externo. Jornal O Estado de São Paulo. São Paulo, 16 de novembro de 1998.

PARKER, Robert \& NOBES, Christopher. International Accounting. EUA: Wiley, 1998. 